\title{
Overbidding and Heterogeneous Behavior in Contest Experiments
}

\author{
Roman M. Sheremeta \\ Argyros School of Business and Economics, Chapman University \\ One University Drive, Orange, CA 92866, U.S.A.
}

January 25,2013

\begin{abstract}
We provide an overview of experimental literature on contests and point out the two main phenomena observed in most contest experiments: (i) overbidding relative to the standard Nash equilibrium prediction and (ii) heterogeneous behavior of ex-ante symmetric contestants. Based on the sample of contest experiments that we review, the median overbidding rate is $72 \%$. We provide different explanations for the overbidding phenomenon, including bounded rationality, utility of winning, other-regarding preferences, probability distortion, and the shape of the payoff function. We also provide explanations for heterogeneous behavior of contestants based on differences in preferences towards winning, inequality, risk and losses, and demographic differences. Furthermore, we suggest mechanisms that can reduce overbidding and induce more homogeneous behavior. Finally, we discuss directions for future research.
\end{abstract}

JEL Classifications: C72, C91, C92, D72, D74

Keywords: experiments, contests, overbidding, heterogeneous behavior

Corresponding author: Roman Sheremeta, sheremet@ chapman.edu

* Much of this survey is based on the work I have done with various coauthors over the course of more than five years. What I learned during those years of collaboration helped me to shape my understanding of the field. I gratefully acknowledge and thank all my coauthors who worked with me on various contest projects. I thank Subhasish Chowdhury, Cary Deck, Shakun Mago, Curtis Price, Jared Rubin, Anya Samak, Ted Turocy, Casper de Vries, Jingjing Zhang, the seminar participants at Chapman University, the University of California at San Diego, the University of Texas at Dallas, and participants at the 2012 International Foundation for Research in Experimental Economics Conference and the 2012 North America Economic Science Association meetings for their comments and valuable feedback. I retain responsibility for any errors. 


\section{Introduction}

Many examples of competition have the property that multiple agents exert costly irreversible efforts while competing for a prize but only one agent receives the prize. Such costly competitions between economic agents are often portrayed as contests. Examples include rentseeking contests, R\&D competitions between firms, patent races, and competitions for promotion. These environments have attracted the attention of many prominent theorists and have yielded a number of interesting theoretical predictions; for a comprehensive review of theoretical literature see Konrad (2009). Some of these predictions have been tested empirically using field data (Prendergast, 1999; Szymanski, 2003). Most of the empirical studies, however, focus solely on investigating whether the pattern of outcomes in contests is consistent with the comparative static predictions, since it is difficult to measure the actual effort expended by players in the field (Ericsson and Charness, 1994).

Controlled laboratory experiments give researchers the ability to measure the actual effort in contests, while controlling for relative abilities of contestants and the amount of noise in the contest. ${ }^{1}$ Almost all experimental studies are based on three canonical models - contests (Tullock, 1980), rank-order tournaments (Lazear and Rosen, 1981), and all-pay auctions (Hirshleifer and Riley, 1978; Nalebuff and Stiglitz, 1983; Hillman and Riley, 1989). For a comprehensive review of a rapidly growing experimental literature on contests, all-pay auctions and tournaments, see Dechenaux et al. (2012). Although certain assumptions underlying the three canonical models are different, all three models assume that (i) players exert costly

\footnotetext{
${ }^{1}$ It is still possible that subjects who are assigned ex-ante symmetric roles in contests may still differ in their skills (abilities) of playing the experimental game (i.e., differences in cognitive ability, understanding the incentives, learning, etc.). However, the luxury of experimental approach is that these "hidden abilities" can be measured and controlled for in the laboratory using different methods and elicitation procedures.
} 
irreversible efforts while competing for a prize and (ii) an individual player's probability of winning the prize depends on the players' relative expenditures.

Contests, all-pay auctions and tournaments have traditionally been applied to different areas of economic analysis. Contests have been commonly used in the study of R\&D races and political or rent-seeking competitions (Millner and Pratt, 1989; Davis and Reilly, 1998; Potters et al., 1998; Sheremeta, 2010, 2011; Sheremeta and Zhang, 2010; Price and Sheremeta, 2011, 2012; Morgan et al., 2012). The commonly observed finding from contest experiments, first documented by Millner and Pratt (1989), is that there is significant overbidding relative to the standard Nash equilibrium prediction. Such overbidding is not desirable, since in the context of rent-seeking competitions where contests have often been applied, a welfare maximizing socialplanner seeks to minimize socially wasteful expenditures (Tullock, 1980). ${ }^{2}$

Rank-order tournaments have been used in the principal-agent, contract design and labor literatures (Bull et al., 1987; Schotter and Weigelt, 1992; Harbring and Irlenbusch, 2011; Sheremeta and Wu, 2011; Agranov and Tergiman, 2013; Eisenkopf and Teyssier, 2013). Contrary to contest experiments, the common finding from tournament experiments, which was first documented by Bull et al. (1987), is that the average effort levels in tournaments are well predicted by theory. Such efforts in rank-order tournaments are usually viewed as valuable because they contribute to the firm's output.

Finally, all-pay auctions have been used in the auction literature and in lobbying and military applications (Barut et al., 2002; Noussair and Silver, 2006; Gneezy and Smorodinsky, 2006; Lugovskyy et al., 2010; Kovenock et al., 2010; Deck and Sheremeta, 2012; and Chowdhury et al., 2013). Similarly to contest experiment, all-pay auction experiments find

\footnotetext{
${ }^{2}$ In the context of R\&D and patent races, however, a social planner may desire the positive externalities generated from increased research spending.
} 
significant overbidding relative to the Nash equilibrium prediction. Also, as in contests, overbidding in all-pay auctions is not desirable.

In this paper, we restrict our attention mostly to contests (Tullock, 1980). The main reasons we focus on contests are that (i) contests have attracted most attention from experimental researchers and (ii) the results and phenomena observed in contest experiments are very robust and demand rigorous and comprehensive explanations. This paper attempts to provide such explanations.

We begin by introducing a simple theoretical contest model in Section 2. In Section 3, we provide an overview of experimental literature on contests and point out the two main phenomena observed in almost all contest experiments: (i) overbidding relative to the standard Nash equilibrium prediction and (ii) heterogeneous behavior of ex-ante symmetric contestants. In Section 4 we provide explanations for the overbidding phenomenon, including bounded rationality, utility of winning, other-regarding preferences, probability distortion, and the shape of the payoff function. We also suggest mechanisms that can reduce overbidding. In Section 5 we provide explanations for heterogeneous behavior of contestants based on differences in preferences towards winning, inequality, risk and losses, and demographic differences. We also discuss several mechanisms that can reduce heterogeneity of individual behavior. Section 6 concludes and suggests directions for future research.

\section{A Simple Contest Model}

Perhaps the simplest contest model is a lottery contest proposed by Tullock (1980). In such a contest, there are $n$ identical risk-neutral players competing for a prize value of $v$. The probability that player $i$ wins the prize depends on player $i$ 's effort $e_{i}$ and the efforts of all other 
$n-1$ players. Specifically, player $i$ 's probability of winning the prize is defined by a contest success function (CSF) (Skaperdas, 1996):

$$
p_{i}\left(e_{i}, e_{-i}\right)=\frac{e_{i}}{\sum_{j=1}^{n} e_{j}} .
$$

Given CSF (1), the expected payoff for player $i$ is

$$
E\left(\pi_{i}\left(e_{i}, e_{-i}\right)\right)=p_{i}\left(e_{i}, e_{-i}\right) v-e_{i} .
$$

That is, the probability of winning the prize $p_{i}\left(e_{i}, e_{-i}\right)$ times the prize value $v$ minus the cost of effort $c\left(e_{i}\right)=e_{i}$. Differentiating (2) with respect to $e_{i}$ and accounting for the symmetric Nash equilibrium leads to a standard solution (Tullock, 1980):

$$
e^{*}=\frac{(n-1)}{n^{2}} v \text {. }
$$

There are no asymmetric equilibria in the lottery contest and the symmetric equilibrium (3) is unique (Szidarovszky and Okuguchi, 1997). Given (3), the probability of winning in the equilibrium is $1 / n$ and the expected payoff is $E\left(\pi^{*}\right)=v / n^{2}$. In a classic formulation of a Tullock contest efforts are considered as wasteful rent-seeking expenditures. The Pareto optimal level of effort is $e^{P O}=0$. In such a case, the probability of winning is still $1 / n$, but the expected payoff is $E\left(\pi^{P O}\right)=v / n$.

\section{Experimental Findings on Contests}

The first attempt to examine a lottery contest using a laboratory experiment dates back to Millner and Pratt (1989). In their experiment, subjects are placed in groups of two (i.e., $n=2$ ) and the composition of the groups changes from period to period. Each period, subjects submit their efforts (bids) in order to win a prize of $\$ 8$ (i.e., $v=8$ ). Given these parameters, the unique equilibrium effort from equation (3) is $e^{*}=v(n-1) / n^{2}=2$. The two main findings of Millner and Pratt (1989) are that (i) average effort is significantly higher than the risk-neutral Nash 
equilibrium prediction (overbidding) and (ii) there is a high variance in individual efforts (heterogeneous behavior). ${ }^{3}$

Since Millner and Pratt (1989), many other experiments have replicated the phenomena of overbidding and heterogeneity of efforts. Table 1 presents a summary of lottery contest experiments with symmetric players. Two main conclusions can be made regarding overbidding. First, overbidding is a widespread phenomenon observed in almost all experimental contest studies. Out of 30 studies, 28 studies document statistically significant overbidding. The median overbidding rate, defined as $\left(e-e^{*}\right) / e^{*}$, is $72 \%$, and in some studies the overbidding rate is so high that subjects on average earn negative payoffs (Abbink et al., 2010; Sheremeta and Zhang, 2010; Price and Sheremeta, 2011, 2012; Chowdhury et al., 2012; Lim et al., 2012; Morgan et al., 2012). Second, the overbidding rate across the 28 studies that find significant overbidding is quite different, ranging from $10 \%$ to $256 \%$. From a first glance it is difficult to ascertain what causes such differences in overbidding rates. However, it is clear that there are many procedural and design differences that may be important. For example, most experiments employ either fixed or random matching protocols (Andreoni and Croson, 2008). When subjects face the same opponents for a number of periods (fixed matching) they may learn how to collude by reducing their efforts (Lugovskyy et al., 2010). ${ }^{4}$ Also, before participating in the contest, subjects are usually endowed with a certain amount of experimental currency that allows them to exert efforts (make bids) in the contest (Price and Sheremeta, 2011, 2012). In some studies, the endowment is

\footnotetext{
${ }^{3}$ Similar phenomena are also observed in all-pay auctions with complete information (Davis and Reilly, 1998; Gneezy and Smorodinsky, 2006; Lugovskyy et al., 2010; Kovenock et al., 2010; Klose and Sheremeta, 2012; Ong and Chen, 2012; Mago and Sheremeta, 2012; Deck and Sheremeta, 2012) and incomplete information (Barut et al., 2002; Noussair and Silver, 2006; Dechenaux and Mancini, 2008; Müller and Schotter, 2010; Hyndman et al., 2012). For a review see Dechenaux et al. (2012).

${ }^{4}$ Collusion is clearly an issue in the context of auctions (see Klemperer, 2002). A common way to deal with this is to randomly re-match subjects after each period of play. However, there is no general agreement on how matching protocol influences individual behavior. In public good games, for example, some studies find more cooperation under random matching, some find more under fixed marching, and some fail to find any difference at all (Andreoni and Croson, 2008; Botelho et al., 2009).
} 
higher than the prize value (i.e., Millner and Pratt, 1989) and in other studies it is lower (Shogren and Baik, 1991). Finally, it is possible that the overbidding rate depends on the number of contestants.

We examine what factors can explain differences in overbidding rates across the 30 studies reported in Table 1 by estimating a simple OLS regression (a unit of observation is an average over an entire study), where the dependent variable is the overbidding rate $\left(e-e^{*}\right) / e^{*}$ and the independent variables are the relative (to the prize value) size of endowment, the number of contestants $n$, a dummy-variable for the fixed matching protocol, and a constant. ${ }^{5}$ The estimated regression (with $* *$ and $* * *$ indicating significance at 0.05 and 0.01 level and standard errors in parentheses) is:

$$
\text { overbidding rate }=\underbrace{0.43^{* *}}_{(0.21)} \text { endowment }+\underbrace{0.20^{* * *}}_{(0.04)} n-\underbrace{0.08}_{(0.17)} \text { fixed }-\underbrace{0.41^{* *}}_{(0.27)} \text { constant } \text {. }
$$

This simple model explains $45 \%$ of variation in the sample (adjusted R-squared is 0.45 ). The regression shows that the overbidding rate increases (i) in the relative size of endowment (pvalue $=0.04)$ and (ii) in the number of contestants (p-value $<0.01)$. The coefficient on the dummy-variable for the fixed matching protocol is negative (as one would expect from collusion) but it is not significant $(\mathrm{p}$-value $=0.65)$. Based on the estimation results presented in (4), the experimenters should expect an average overbidding rate of about $22 \%$ when using the endowment equal to the prize value (endowment $=1)$ in a two-player contest $(n=2)$ with random matching (fixed $=0)$.

Overall, the summary of the 30 experimental studies on contests reported in Table 1 and the estimation results of a simple OLS regression pose a number of interesting questions: Why do subjects overbid relative to the standard Nash equilibrium prediction? Why does overbidding

\footnotetext{
${ }^{5}$ We have also included a dummy-variable for those experiments that last for only one period. The dummy-variable is positive, but insignificant.
} 
increase in the relative size of endowment and the number of players? The next section provides explanations to these questions.

\section{Overbidding in Contests}

\subsection{Bounded Rationality}

We begin by discussing perhaps one of the most commonly cited explanations for overbidding - bounded rationality. Potters et al. (1998) conjecture that most subjects are likely to make mistakes, which add noise to the Nash equilibrium solution and thus may cause overbidding. Sheremeta (2011) tests this conjecture by applying the quantal response equilibrium (QRE) developed by McKelvey and Palfrey (1995). In the Nash equilibrium, players must only put positive probability on playing strategies that are best responses to other players' equilibrium strategies. In the QRE, player $i$ plays a mixed strategy $\sigma_{i}$ in which the probability of playing a pure strategy $e_{i}$ is increasing in the expected payoff $E\left(\pi_{i}\left(e_{i}, \sigma_{-i}\right)\right)$ of that strategy $e_{i}$ given that others are playing the equilibrium mixed strategy $\sigma_{-i}$. The most commonly used specification of the QRE is the logistic QRE, where the player $i$ 's equilibrium probability of playing $e_{i}$ is given by:

$$
\sigma_{i}\left(e_{i}\right)=\frac{\exp \left(E\left(\pi_{i}\left(e_{i}, \sigma_{-i}\right)\right) / \mu\right)}{\int_{e} \exp \left(E\left(\pi_{i}\left(e, \sigma_{-i}\right)\right) / \mu\right)},
$$

where $\mu>0$ is a parameter that describes the level of noise in the decision making process. If $\mu \rightarrow 0$, then the Nash equilibrium effort $e^{*}$ is chosen with probability one. If $\mu \rightarrow \infty$, then each effort $e_{i}$ between 0 and the maximum allowed effort level (endowment in Table 1) is equally likely to be chosen.

An implication of the QRE is that subjects who have higher endowments (and thus larger strategy space to make mistakes) are more likely to overbid. The intuition is simple. Consider a 
subject who is completely confused and does not understand the rules of the game (i.e., $\mu \rightarrow \infty$ ).

According to the QRE, such a subject should make his decision by randomly choosing any effort level $e_{i}$ between 0 and the endowment level. So, the higher is the endowment, the more likely it is that the confused subject chooses an effort that is higher than the Nash equilibrium. ${ }^{6}$ On the contrary, the lower the endowment, the lower is the probability that the confused subject overbids.

Sheremeta (2011) explicitly tests the predictions of the QRE model by conducting two experimental treatments. In each treatment, four subjects $(n=4)$ compete in a lottery contest for a prize value of $v=120$. In one treatment, subjects receive the endowment of 60 and in the other treatment subjects receive the endowment of 40 . Note that the endowment is not binding relative to the Nash equilibrium of 22.5 (i.e., $e^{*}=v(n-1) / n^{2}=22.5$ ). Figure 1 displays the expected average effort at the QRE as a function of $\mu$ and endowment. When $\mu \rightarrow 0$, the behavior is consistent with the Nash equilibrium. When $\mu \rightarrow \infty$, players move closer to a random play, and thus the average effort approaches 30 (overbidding) for the endowment of 60 and it approaches 20 (underbidding) for the endowment of 40. Therefore, if subjects make substantial level of mistakes, then the average effort should be significantly higher in the treatment with the endowment of 60. Sheremeta (2011) finds that the actual average effort is 29.3 when the endowment is 60 and it is 21.0 when the endowment is 40 , consistent with the predictions of the QRE. ${ }^{7}$

\footnotetext{
${ }^{6}$ In interpreting these results some caution is advised since changing the endowment also changes subjects' wealth levels. If individuals have more wealth, they may be more willing to spend more of it regardless of the level of mistakes. Future research is needed to clearly separate these effects.

${ }^{7}$ There are two potential explanations as to why subjects make mistakes. First, it is possible that subjects hold incorrect beliefs about the actions chosen by their opponents. Second, subjects may simply make errors in their own actions. The first explanation is less likely to be true. The main reason is that the best-response functions in contests are structured in such a way that if a subject believes that the opponent is going to either make higher or lower than the equilibrium effort, his best response is to always exert lower than the equilibrium effort. Therefore, errors in beliefs cannot explain overbidding. There is also substantial evidence of overbidding in sequential contests
} 
The findings of Sheremeta (2011) can explain why only 2 out of 30 studies reported in Table 1 do not find significant overbidding (i.e., Shogren and Baik, 1991; Schmidt et al., 2005). In both of these studies, the endowment is very small relative to the prize value. In Shogren and Baik (1991) subjects cannot exert efforts higher than 24, while the prize value is 32. In Schmidt et al. (2005) subjects can exert efforts only up to 20 , while the prize value is 72 . Therefore, it is not surprising that these two studies do not find overbidding.

Bounded rationality can also explain why overbidding increases in the number of players. Lim et al. (2012) use the QRE to show that overbidding increases in the number of players $n$ and find support for this prediction in a laboratory experiment. Specifically, they find that when there are two players $(n=2)$ in a contest, the overbidding rate $\left(e-e^{*}\right) / e^{*}$ is $30 \%$. When the number of players increases to 4 and then to 9 , the overbidding rate increases to $61 \%$ and then further to $230 \% .^{8}$ Therefore, it appears that bounded rationality can explain why the overbidding rate increases (i) in the relative size of endowment and (ii) in the number of contestants.

\subsection{Utility of Winning}

In addition to bounded rationality, another oft-cited explanation for overbidding is a nonmonetary utility of winning. The theoretical predictions in Section 3 are based on the assumption that subjects care only about the monetary value of the prize (i.e., v). However, subjects also may care about winning itself. Schmitt et al. (2004) argue that the persistent overbidding in numerous experimental studies (including their own) suggests that such behavior is not merely the result of subjects' mistakes or misunderstanding of the experimental environment. They

(Fonseca, 2009). In such contests, subjects first observe the actions of their opponents and then make their decisions. However, even when subjects have perfect information about the actions of their opponents, they still choose to bid more than the equilibrium.

${ }^{8}$ Similar findings on the impact of the number of contestants on the overbidding rate are documented by Anderson and Stafford (2003), Sheremeta (2011) and Morgan et al. (2012). 
propose that winning may be a component in a subject's utility. Sheremeta (2010) tests this hypothesis by directly eliciting such a utility from subjects. In the experiment, subjects participated in 30 periods of play in a four-player contest (i.e., $n=4$ ) with a prize value of 120 (i.e., $v=120$ ). At the end of the experiment, subjects were asked to submit their efforts for a prize value of 0 (i.e., $v=0$ ). Subjects were explicitly told that they would have to pay for their efforts and that they would not receive any monetary benefit in case they won.

If subjects value only monetary payoffs, they should not exert any effort when the monetary prize value is zero. However, if subjects derive utility from winning itself, they may choose to exert positive efforts even when there is no monetary prize. ${ }^{9}$ Sheremeta (2010) finds that more than $40 \%$ of subjects exert positive efforts in the contest with a prize value of zero. Moreover, efforts in a contest with a zero prize are correlated with efforts in contests with a strictly positive prize. Figure 2 displays the correlation between an effort for a prize of $v=0$ and an average (over 30 periods of play) effort for a prize of $v=120$. According to the theoretical prediction, the Nash equilibrium effort is $e^{*}=v(n-1) / n^{2}=22.5$ when the prize is $v=120$, and $e^{*}=0$ when the prize is $v=0$. Figure 2 shows that there is substantial heterogeneity in efforts, and subjects who exert higher efforts for the prize of 0 also exert higher efforts for the prize of 120 (Spearman's correlation coefficient is 0.31 , p-value $<0.01$ ). Therefore, it appears that in addition to monetary utility, some subjects derive non-monetary utility of winning and such a utility can partially explain overbidding.

Although the findings of Sheremeta (2010) have been replicated by other studies (Price and Sheremeta, 2011, 2012; Brookins and Ryvkin, 2011; Cason et al., 2011; Mago et al., 2012),

\footnotetext{
${ }^{9}$ Delgado et al. (2008) suggest that another explanation for overbidding, besides a utility of winning, is a disutility of losing. They provide evidence for the disutility of losing in the context of a first-price auction. Currently, there is no study examining the disutility of losing as a possible explanation for overbidding in contests. What is even a more interesting question is how to distinguish the utility of winning from the disutility of losing. These are interesting questions for future research.
} 
there is still more scope for future research. For example, when eliciting utility of winning there may be several confounds, such as an experimenter demand effect (Zizzo, 2010) - subjects may feel obligated to submit efforts for the prize of value zero because the experimenter has asked them to do so. It may be also the case that subjects who make errors in assessing their effort strategies for a prize of positive value (see the discussion in Section 4.1) are also likely to make errors in bidding for a prize of value zero. Finally, even if subjects derive a utility of winning, the exact specification of such a utility function is not clear.

One way to incorporate the utility of winning into a contest model described in Section 3, is to assume that in addition to the prize value $v$, individuals also have an additive utility of winning $w$ (Sheremeta, 2010). Therefore, the updated expected payoff (2) of player $i$ can be written as

$$
E_{w}\left(\pi_{i}\left(e_{i}, e_{-i}\right)\right)=p_{i}\left(e_{i}, e_{-i}\right)(v+w)-e_{i}
$$

Differentiating (6) with respect to $e_{i}$ and accounting for the symmetric Nash equilibrium gives us a new equilibrium effort, which is a function of both a monetary $(v)$ and a non-monetary $(w)$ component:

$$
e_{w}^{*}=\frac{(n-1)}{n^{2}}(v+w) \text {. }
$$

From (7) one can easily verify that $\partial e_{w}^{*} / \partial w=(n-1) / n^{2}>0$. An implication of this result is that compared to the standard Nash equilibrium effort $e^{*}$ described by (3), equilibrium effort $e_{w}^{*}$ described by (7) implies overbidding (i.e., $e_{w}^{*}>e^{*}$ ).

It is possible that the utility of winning is not additive and is not invariant to the value of the monetary prize $v$. In such a case, a correct specification of utility of winning would be $w=w(v)$. It is also possible that the utility of winning depends on the number of contestants, 
i.e., $w=w(n)$. As mentioned before, the correct specification of the utility of winning function is an important question for future research.

\subsection{Other-Regarding Preferences}

Related to the utility of winning, studies show that overbidding may be driven by spiteful preferences and inequality aversion (Herrmann and Orzen, 2008; Bartling et al., 2009; Fonseca, 2009; Cason et al., 2011; Balafoutas et al., 2012; Mago et al., 2012). ${ }^{10}$ Balafoutas et al. (2012), for example, elicit other-regarding preferences using a binary choice elicitation procedure of Bartling et al. (2009), and find that spiteful and inequality-averse subjects exert significantly higher efforts in real-effort contests. Following the convention established in evolutionary game theory, Mago et al. (2012) propose a theoretical model in which subjects care not only about the utility of winning $w$ but also about the absolute difference in payoffs, i.e., $E\left(\pi_{i}\left(e_{i}, e_{-i}\right)\right)-$ $s \frac{1}{n} \sum_{j} E\left(\pi_{j}\left(e_{j}, e_{-j}\right)\right)$, where $s$ is the interdependent social payoff parameter. Accounting for the behavioral factors captured by $w$ and $s$, the expected utility for a risk-neutral player $i$ is given by

$$
\begin{aligned}
U_{i}\left(e_{i}, e_{-i}\right) & =E_{w}\left(\pi_{i}\left(e_{i}, e_{-i}\right)\right)-s \frac{1}{n} \sum_{j} E_{w}\left(\pi_{j}\left(e_{j}, e_{-j}\right)\right)= \\
& =\left(p_{i}\left(e_{i}, e_{-i}\right)(v+w)-e_{i}\right)-s \frac{1}{n} \sum_{j}\left(p_{j}\left(e_{j}, e_{-j}\right)(v+w)-e_{j}\right) .
\end{aligned}
$$

The utility function (8) is most commonly used in evolutionary contest theory (Leininger, 2003; Hehenkamp et al., 2004; Riechmann, 2007). The idea is that the objective of a contestant is not necessarily to maximize the expected payoff $E_{w}\left(\pi_{i}\left(e_{i}, e_{-i}\right)\right)$, but to "survive" by outperforming all rivals. This quest to seek a higher payoff relative to others is an evolutionary stable strategy, and it is also consistent with 'spite' (Hamilton, 1970). Mago et al. (2012)

\footnotetext{
${ }^{10}$ Sheremeta and $\mathrm{Wu}$ (2011) and Eisenkopf and Teyssier (2013) report similar findings in the context of rank-order tournaments.
} 
interpret $s>0$ as status-seeking behavior, i.e., contestants strive to obtain a higher relative payoff within the group. Herrmann and Orzen (2008) interpret $s>0$ as aversion towards disadvantageous inequality. The utility function (7) also can capture pro-social behavior if $s<0$, i.e., contestants have preferences to increase the payoff of the entire group.

Differentiating (8) with respect to $e_{i}$ and accounting for the symmetric Nash equilibrium gives the equilibrium effort

$$
e_{w s}^{*}=\frac{(n-1)}{n(n-s)}(v+w)
$$

The equilibrium effort (9) increases in the utility of winning $w$ (i.e., $\partial e_{w s}^{*} / \partial w>0$ ) and increases in the status-seeking parameter $s$ (i.e., $\partial e_{w s}^{*} / \partial s>0$ ).

In their experiment, Mago et al. (2012) find that $51 \%$ of subjects indicate positive utility of winning $(w>0)$ and $67 \%$ of subjects behave as status-seekers $(s>0)$. These findings suggest that overbidding in contests can also be explained by a combination of a utility of winning and relative payoff maximization.

\subsection{Probability Distortion}

Baharad and Nitzan (2008) illustrate theoretically how probability distortion of the CSF (1) can lead to overbidding. Building on the theory of Tversky and Kahneman (1992), Baharad and Nitzan use an inverse S-shaped probability weighting function. According to this theory, individuals assign a distorted value $d(p)$ to the objective probability $p$. Thus, instead of CSF (1), subject's perceived probability of winning is given by:

$$
d(p)=\frac{p^{\beta}}{\left(p^{\beta}+(1-p)^{\beta}\right)^{1 / \beta}} .
$$

Figure 3 illustrates the distortion function (10), assuming $\beta=0.61$, as in Tversky and Kahneman (1992). When facing relatively small probabilities $(p<0.33)$ the individual is 
optimistic, since the distorted probability of winning $d(p)$ is higher than the objective probability $p$. When facing relatively large probabilities $(p>0.33)$ the individual is pessimistic, since $p$ is underestimated.

Given the distortion function (10), the expected payoff for an individual $i$ is

$$
E_{d}\left(\pi_{i}\left(e_{i}, e_{-i}\right)\right)=d\left(p_{i}\left(e_{i}, e_{-i}\right)\right) v-e_{i}
$$

Differentiating (11) with respect to $e_{i}$ and accounting for the symmetric Nash equilibrium gives the equilibrium effort

$$
e_{d}^{*}=\frac{(n-1)}{n^{\beta}\left(1+(n-1)^{\beta}\right)^{1 / \beta}}\left(\beta-\frac{1-(n-1)^{\beta-1}}{1+(n-1)^{\beta}}\right) v
$$

When comparing $e_{d}^{*}$ described by (12) to a standard Nash equilibrium effort $e^{*}$ described by (3), we find that the overbidding rate $\left(e_{d}^{*}-e^{*}\right) / e^{*}$ depends on the number of contestants $n$. For a relatively small number of contestants, probability distortion may result in underbidding. For example, with $n=2$ and $\beta=0.61$, the equilibrium effort (12) with distorted probability (10) is $e_{d}^{*}=0.13 v$, while the equilibrium effort (3) with no distortion is $e^{*}=0.25 v$. The intuition is that with only two contestants, the relatively high winning probabilities are underestimated and this substantially reduces the incentive to exert efforts in the contest. ${ }^{11}$ However, when the number of contestants is relatively large, probability distortion implies overbidding relative to the standard Nash equilibrium (i.e., $e_{d}^{*}>e^{*}$ ). For example, with $n=15$ and $\beta=0.61$, the equilibrium effort (12) with distorted probability is $e_{d}^{*}=0.07 v$, while the equilibrium effort (3) with no distortion is $e^{*}=0.06 v$. Note that the fact that overbidding increases in the number of players (due to distorted probabilities) can also help explain different overbidding rates reported in Table 1, and the estimation results reported in (4).

\footnotetext{
${ }^{11}$ Obviously, if in addition to distorted probabilities subjects also derive an additive utility of winning as in Section 4.2, then the updated equilibrium effort $e_{w d}^{*}=0.13(v+w)$ could be still greater than $e^{*}=0.25 v$, depending on the relative magnitude of the utility of winning (i.e., $e_{w d}^{*} / e^{*}=0.52(1+w / v)$ ).
} 
Parco et al. (2005) and Amaldoss and Rapoport (2009) apply the distorted probability function (10), combined with a utility of winning, to explain the pattern of the data observed in their contest experiments. They find that behavior of contestants can be well explained by a combination of a utility of winning and a distorted probability function.

\subsection{The Shape of the Payoff Function}

Subjects participating in a contest experiment are usually inexperienced. Therefore, it may be difficult for them to understand the precise incentives underlying the game. As described in Section 4.4, subjects may have distorted perception of probabilities (Tversky and Kahneman, 1992). They may also find it difficult to calculate the exact expected payoff, since the feedback they receive after each repetition of the contest game is very noisy: a subject either wins the prize or not. Moreover, it can be shown that the payoff function (2) is relatively flat around the Nash equilibrium. Figure 4 shows the expected payoff in a four-player contest $(n=4)$ as a function of effort $e$, given that the opponents play the Nash equilibrium $e^{*}$ (the value of the prize $v$ is normalized to 1 ). Given these parameters, the effort that maximizes the expected payoff is $e^{*}=$ $0.18 v$. It is easy to verify that even when the overbidding rate is $100 \%$ (i.e., $\left.\left(e-e^{*}\right) / e^{*}=1\right)$ subjects can still make almost $50 \%$ of the equilibrium payoff.

Chowdhury et al. (2012) design an experiment aimed at examining how individual behavior is impacted by the specification of the payoff function (2). In a two-by-two design, they vary whether the prize is assigned probabilistically (i.e., efforts determine the probabilities of winning the prize) or proportionally (i.e., efforts determine the shares of the prize) and whether the cost function is linear or convex (see Figure 4), while holding the risk-neutral Nash equilibrium effort level constant. They find that compared to the probabilistic CSF, the 
proportional rule results in effort levels that are closer to the risk-neutral prediction. ${ }^{12}$ The variance in individual efforts is also lower under the proportional rule and the distribution of individual efforts converges toward Nash equilibrium over time. Combining the proportional rule with a convex cost function further strengthens these results.

Fallucchi et al. (2012) also find that using the proportional rule instead of the probabilistic CSF reduces overbidding. Masiliunas et al. (2012) further document that overbidding is also reduced when subjects play against computer opponents with pre-determined actions that subjects know when they make their choices.

Overall, the results of Chowdhury et al. (2012), Masiliunas et al. (2012) and Fallucchi et al. (2012) suggest that overbidding in contests can be explained in part by the facts that (i) subjects have a hard time calculating the expected payoffs, (ii) the costs of deviation from the Nash equilibrium are relatively low, and (iii) there is not enough feedback for subjects to learn how the contest works.

\subsection{How to Reduce Overbidding}

We discussed in Section 3 that effort expenditures in contests are wasteful, in a sense that higher overbidding rates imply lower payoffs. Therefore, given the high rates of overbidding reported in Table 1, it is important to examine how one can reduce overbidding in contests. Recently, Price and Sheremeta (2012) showed that when subjects earn their endowments before participating in a lottery contest, their subsequent efforts in contests are lower than when endowments are given to them freely as "house money" (i.e., the money subjects risk comes from the experimenter rather than their own pockets). Furthermore, Price and Sheremeta (2011)

\footnotetext{
${ }^{12}$ Note that the proportional rule eliminates the utility of winning and thus less overbidding also might be due to the absence of the utility of winning,
} 
show that subjects exert lower efforts when, instead of receiving money as a lump sum, they receive a small portion each period. Therefore, one way to reduce overbidding would be to let subjects earn their money and/or make this money available to them gradually during the duration of the entire experiment.

Another way to reduce overbidding is to promote pro-social behavior among contestants. One such mechanism is communication. Cason et al. (2012), for example, find that when two contestants (or two competing groups) are allowed to communicate, they usually collude by exerting very low efforts (close to zero). Even when communication is not possible, there are other mechanisms through which subjects can still learn to reduce their efforts. Savikhin and Sheremeta (2013), for example, find that subjects reduce efforts in a lottery contest if they simultaneously participate in a public good game. Mago et al. (2012) find that subjects exert lower efforts in contests when their identities are reveled through photo display. The authors argue that photo display reduces social distance and enhances pro-social behavior, leading subjects to behave more cooperatively.

Related to the question of how to reduce overbidding, and perhaps an even more fundamental question is whether subjects can avoid a potentially wasteful competition in a contest altogether. Kimbrough and Sheremeta $(2012,2013)$ propose side-payments as one such mechanism, where one player (proposer) can offer a side-payment to another (responder) in order to avoid potentially wasteful overbidding. Their experimental results indicate that subjects learn how to avoid contests even in the case when side-payments are not contracted. Kimbrough et al. (2011, 2013) suggest a random device (a coin flip) as a conflict resolution mechanism. They find that, instead of competing in a contest, subjects often use a fair coin flip (even in the 
case when one player is relatively stronger than another or when the outcome of the coin flip is not binding).

\section{Heterogeneous Behavior in Contests}

Figure 5 displays a typically observed distribution of effort levels by subject. The data are taken from Chowdhury et al. (2012). Subjects are ordered by increasing average effort choices, which are indicated by diamonds. The boxplots display within-subject variation of effort. The Nash equilibrium prediction is that all subjects should choose the same effort of 15 (i.e., $\left.e^{*}=v(n-1) / n^{2}=15\right)$, since in the experiment there are $n=4$ players competing for a prize of $v=80$. It is important to emphasize again that there are no asymmetric equilibria in a lottery contest and the symmetric equilibrium is unique. ${ }^{13}$ Contrary to the theoretical predictions, Figure 5 illustrates substantial between-subject heterogeneity (see the distribution of the diamonds) and within-subject heterogeneity (see the boxplots).

Similar results are also found in Sheremeta and Zhang (2010), Sheremeta (2011), Masiliunas et al. (2012), and other studies reported in Table 1. An obvious and interesting question is: What can explain the between-subject and within-subject heterogeneity? In Sections 5.1 and 5.2, we provide different preference-based and demographic-based explanations for between-subject heterogeneity. ${ }^{14}$ In Section 5.3, we provide explanations for within-subject heterogeneity.

\footnotetext{
${ }^{13}$ It is possible for multiple (asymmetric) equilibria to arise if one formally introduces behavioral considerations into a theoretical model of contests (see for example, Gill and Stone, 2010; Chowdhury and Sheremeta, 2011; Cornes and Hartley, 2012; Minor, 2012).

${ }^{14}$ Part of the observed heterogeneity can be also explained by the QRE model. In the QRE subjects draw their efforts from a mixed strategy distribution, and thus we should observe within-subject heterogeneity. Also, if we assume that different subjects have different cognitive abilities (and thus make different levels of mistakes), the QRE could also explain between-subject heterogeneity. Currently, there is no formal analysis of the QRE which would incorporate all these elements to explain behavior in contests, and such an analysis would be an important contribution.
} 


\subsection{Heterogeneous Preferences}

In Section 4.2, we suggested that in addition to monetary utility subjects may also have a non-monetary utility of winning. Moreover, as shown in Figure 2, some subjects have a higher valuation for winning than others. Therefore, one explanation for between-subject heterogeneity is heterogeneity of preferences towards winning (Sheremeta, 2010). Another explanation comes from the discussion in Section 4.3. Specifically, we have suggested that subjects have otherregarding preferences, which are correlated with efforts in contests (Herrmann and Orzen, 2008; Balafoutas et al., 2012; Mago et al., 2012); and therefore, differences in these preferences can explain heterogeneous behavior of contestants.

In addition to differences in other-regarding preferences, it is well documented that subjects have heterogeneous preferences towards risk, with most subjects being risk-averse (Holt and Laury, 2002). The equilibrium effort in (3) is based on the assumption that contestants are risk-neutral, but the standard result from the theoretical literature is that (unlike in first-price auctions) risk aversion implies lower efforts in contests (Hillman and Katz, 1984; Skaperdas and Gan, 1995). ${ }^{15}$ These predictions are supported by several experimental studies (Millner and Pratt, 1991; Schmidt et al., 2005; Sheremeta and Zhang, 2010; Cason et al., 2011; Sheremeta, 2011), which find that risk-averse subjects exert lower efforts in lottery contests than risk-neutral or risk-seeking subjects. So in addition to heterogeneous preferences towards winning and others' payoffs, heterogeneous behavior in contests can be also explained by differences in risk preferences.

Cornes and Hartley (2012) propose yet another explanation based on loss aversion theory of Kahneman and Tversky (1979). They incorporate loss aversion into a standard contest model

\footnotetext{
${ }^{15}$ Although see Konrad and Schlesinger (1997) for a counter example.
} 
by assuming that player $i$ puts a weight of $\lambda>1$ if he loses the contest. In such a case the expected payoff (2) can be re-written as

$$
E\left(\pi_{i}\left(e_{i}, e_{-i}\right)\right)=p_{i}\left(e_{i}, e_{-i}\right)\left(v-e_{i}\right)+\left(1-p_{i}\left(e_{i}, e_{-i}\right)\right) \lambda\left(-e_{i}\right)
$$

Differentiating (13) with respect to $e_{i}$ and accounting for the symmetric Nash equilibrium gives the effort level of

$$
e_{\lambda}^{*}=\frac{(n-1)}{(\lambda-1)(n-1)^{2}+n^{2}} v
$$

The comparative static prediction is that the equilibrium effort (14) decreases in the loss aversion parameter $\lambda$ (i.e., $\partial e_{\lambda}^{*} / \partial \lambda<0$ ). Note that, as with risk-aversion, loss-aversion implies underbidding.

Kong (2008) conducted an experiment to test the predictions of Cornes and Hartley (2012). In the first stage of the experiment, subjects were classified into more and less lossaverse according to elicited measures of each subject's loss aversion (Kahneman et al., 1990). Comparing efforts of the two groups, Kong (2008) finds that, as predicted by Cornes and Hartley (2012), more loss-averse subjects exert lower efforts in contests. However, for any degree of loss aversion, there is significant overbidding (not predicted by loss aversion). Therefore, although loss aversion cannot explain the overbidding phenomenon, it can explain heterogeneous behavior of individuals in contests. ${ }^{16}$

\subsection{Demographic Differences}

So far we have discussed preference-based explanations for subjects' heterogeneous behavior in contests. But perhaps the demographic differences are even more important. When a

\footnotetext{
${ }^{16}$ For theoretical considerations of loss aversion in rank-order tournaments see Gill and Stone (2010) and for experimental investigation see Gill and Prowse (2012) and Eisenkopf and Teyssier (2013). For implications of loss aversion in all-pay auctions see Ernst and Thöni (2010), Müller and Schotter (2010), and Klose and Sheremeta (2012).
} 
subject comes to a laboratory experiment, she comes as an individual with certain demographic and individual characteristics that may have even influenced her decision to participate in the experiment in the first place. So, it should not be surprising that in the experiment subjects behave differently, although ex-ante they have symmetric roles. Although there is no systematic study examining how demographic and individual differences impact behavior in contests, there are several studies that may help shed some light.

Perhaps one of the most important demographic differences that impact individual behavior in contests is gender (Mago et al., 2011; Brookins and Ryvkin, 2011; Price and Sheremeta, 2012). ${ }^{17}$ Price and Sheremeta (2012), for example, find that on average women exert $25 \%$ higher efforts in lottery contests than men. Figure 6 displays the 3-period moving average effort by gender across all 30 periods of the experiment. The Nash equilibrium prediction is that both women and men should choose the same effort of 22.5 (i.e., $e^{*}=v(n-1) / n^{2}=22.5$ ), since in the experiment there are $n=4$ players competing for a prize of $v=120$. It is clear, however, that both women and men overbid relative to the Nash equilibrium. Moreover, women persistently exert higher efforts than men throughout the experiment. Similar results are reported by Mago et al. (2011) in the setting of the best-of-three contests and Brookins and Ryvkin (2011) in the setting of incomplete information contests. These findings are also consistent with research on gender effects in auctions. Ham and Kagel (2006) and Casari et al. (2007), for example, find that women overbid more than men in common value auctions. Chen et al. (2013) find that women bid significantly higher and earn significantly less than men in the first-price auctions.

\footnotetext{
17 There is also a large experimental literature examining gender attitudes toward tournaments. Niederle and Vesterlund (2007), for example, design an experiment in which subjects can choose whether to enter a tournament or to be paid based on a piece-rate. They find that while the performance of men and women is not statistically different, men choose to participate in the tournament significantly more often than women. Niederle and Vesterlund conclude that women "shy away from competition". These findings have been replicated by other studies (e.g., Cason et al., 2010; Balafoutas and Sutter, 2012; Price, 2012).
} 
Finally, Ong and Chen (2012) find that women overbid more than men in all-pay auctions. It is intriguing that gender effects are similar in contests and auctions; however, more research is needed to examine the exact causes of such effects. Disregarding the causes for this gender difference in behavior, the fact that women overbid more than men can partially explain heterogeneous efforts in contest experiments. ${ }^{18}$

Another demographic difference that can explain heterogeneous behavior in contests is religiosity. Price and Sheremeta (2012) find that subjects who indicate that "religion is very important in daily life" make $26 \%$ lower efforts in contests (see Figure 7). It is possible that more religious subjects are more risk averse and thus exert lower efforts in contests (Hilary and Hui, 2009). However, Price and Sheremeta (2012) find that religiosity is a significant predictor of effort expenditures even after controlling for risk preferences. Another possibility is that more religious subjects are more pro-social (Ahmed, 2009; Benjamin et al., 2012) and more compassionate towards their counterparts (Batson et al., 1993; Regnerus et al., 1998), and thus they may yield the competition in contests in favor of others. Disregarding the exact reasons why religiosity impacts individual efforts in contests, it can help explain the observed heterogeneity of behavior.

\subsection{Learning and Hot Hand}

Previous Sections 5.1 and 5.2 provided a number of alternative explanations, based on preferences and demographics, for between-subject heterogeneity. In this section we focus on reasons for within-subject heterogeneity of effort.

\footnotetext{
${ }^{18}$ As a result of more overbidding, women receive significantly lower earnings from contests than men, suggesting that the ex-ante decision to "shy away from competition" (Niederle and Vesterlund, 2007) may actually be rational.
} 
In Section 4.1, we have suggested that the QRE model can help explain overbidding in contests. According to the QRE model, a player draws an effort level $e_{i}$ from a mixed strategy distribution $\sigma_{i}$ (see equation 5). Therefore, within-subject heterogeneity of effort can be explained by the QRE model. It is unlikely, however, that mistakes and errors are the only reasons why the same subject makes different efforts over the course of the experiment.

At the beginning of the experiment most subjects overbid, so the best response is to reduce individual effort. Davis and Reilly (1998) were arguably the first to recognize that subjects learn to reduce their efforts in contests over the course of the experiment. Their findings have been replicated by numerous other studies (Herrmann and Orzen, 2008; Fonseca, 2009; Sheremeta, 2010, 2011; Price and Sheremeta, 2011, 2012; Brookins and Ryvkin, 2011; Mago et al., 2012). Figure 8 displays a typical pattern of the average effort (with standard errors) over the span of the experiment. The data are taken from Mago et al. (2012). Note that as subjects become more experienced, the average effort decreases, but remains significantly higher than the Nash equilibrium prediction. Moreover, even in the last periods of the experiment, efforts are heterogeneous, which is demonstrated by the error bars.

Schmitt et al. (2004) point out another reason why individual efforts may fluctuate over the course of the experiment. Specifically, they find that subjects who won in period $t-1$ are more likely to make higher efforts in period $t$. Similar results are reported by Sheremeta and Zhang (2010) and Sheremeta (2011). Note that when documenting such correlations, the authors usually control for strategic uncertainty by including efforts as dependent variables. Sheremeta and Zhang (2010) point out the similarities of correlation between winning in period $t-1$ and higher efforts in period $t$ to a "hot hand" phenomenon found in the gambling literature - belief in a positive autocorrelation of a non-autocorrelated random sequence (Gilovich et al., 1985; Chau 
and Phillips, 1995; Croson and Sundali, 2005). Therefore, it appears that both learning and hot hand response by subjects may help explain within-subject variation of effort.

\subsection{How to Reduce Heterogeneity}

In the context of labor markets, where contest-like incentive schemes are commonly applied, a high variance in individual effort can impose a substantial cost on employers and decrease the overall efficiency of the work place (Lazear, 1999, 2000). Therefore, it is imperative to find ways how to reduce heterogeneity of individual behavior (Bull et al., 1987; Eriksson et al., 2009). ${ }^{19}$ There is no trivial solution to this problem. As we pointed out in Sections 5.2 and 5.3, the likely causes of heterogeneous behavior in contests are differences in individual preferences and demographic differences. It is hard to imagine a mechanism that would homogenize individual preferences towards winning, inequality, risk and losses. Perhaps even harder (if not impossible) would be to eliminate demographic differences. Nevertheless, we want to point out three alternative mechanisms that may reduce heterogeneity of behavior that is due to subjects making mistakes in contests: (i) group decision-making, (ii) feedback, and (iii) simplified payoff functions. All three mechanisms are targeted to reduce subjects' cognitive load and enhance subjects' learning of the contest environment (Devetag and Warglien, 2003; Burks et al., 2009).

It is well documented that groups are better at making decisions that are more in line with game-theoretic predictions than individuals (Charness and Sutter, 2012). One implication of this result is that groups should choose more homogeneous efforts in contests since theory predicts a

\footnotetext{
${ }^{19}$ It is also well documented that, theoretically (Baik, 1994; Stein, 2002), heterogeneity between players leads to lower aggregate effort. These predictions are also supported by laboratory experiments (Davis and Reilly, 1998; Anderson and Stafford, 2003; Fonseca, 2009; Anderson and Freeborn, 2010; Kimbrough et al., 2011). Therefore, in addition to ex-post negative effect of heterogeneous behavior, heterogeneity may negatively impact strategic behavior in contests ex-ante.
} 
unique equilibrium defined by (3). Sheremeta and Zhang (2010) test this conjecture by comparing efforts chosen by groups of two subjects versus efforts chosen by individual subjects. They find that group efforts are more homogeneous and result in $25 \%$ lower efforts than individual efforts. As a result, groups receive significantly higher and more homogeneous payoffs than individuals. Sheremeta and Zhang suggest that groups perform better because they reduce individual mistakes through group communication and they learn faster than individuals.

Another mechanism that may help subjects to learn faster is feedback. Mago et al. (2012) experimentally examine different levels of feedback in contests. In some experimental sessions, subjects only receive feedback about whether they won the contest or not. In other sessions, subjects receive full feedback about all group members' efforts. Mago et al. find that providing information feedback about others' efforts makes effort levels more uniform within a given group, and thus reduces between-subject heterogeneity. Fallucchi et al. (2012) find that not only does feedback reduce heterogeneity, but it can also reduce overbidding in the long-run (i.e., when the experiment is repeated for 60 periods).

Finally, it is possible to reduce between-subject as well as within-subject heterogeneity by using a more simplified payoff function. We have already discussed in Section 4.5 that using the proportional rule, instead of the probabilistic CSF, reduces overbidding (Chowdhury et al., 2012; Fallucchi et al., 2012; Masiliunas et al., 2012). Moreover, Chowdhury et al. (2012) find that not only does the proportional rule reduce overbidding, but it also significantly decreases between-subject and within-subject heterogeneity. This is mainly because the proportional rule gives subjects an opportunity to better learn the payoff structure of the contest, and thus subjects learn to make fewer errors. 


\section{Discussion and Conclusion}

Contests are prevalent in the fields of economics, management, biology, law and political science and have attracted the attention of many theorists. It is difficult, however, to test theoretical predictions in the field because efforts are unobservable. For that reason, researchers have turned to controlled laboratory experiments that allow measuring the actual efforts in contests, while controlling for relative abilities of contestants and the amount of noise in the contest; for a review of experimental literature see Dechenaux et al. (2012).

In this paper, we provide an overview of experimental literature on lottery contests and point out the two main phenomena observed in almost all contest experiments: (i) overbidding relative to the standard Nash equilibrium prediction and (ii) heterogeneous behavior of ex-ante symmetric contestants.

We provide a number of explanations in Sections 4.1-4.5 for the overbidding phenomenon, including (1) bounded rationality, (2) utility of winning, (3) other-regarding preferences (spite, inequality-aversion), (4) probability distortion, and (5) the shape of the payoff function. Obviously, these explanations are not exhaustive. Other potential candidates, for example, are regret (Engelbrecht-Wiggans and Katok, 2007; Filiz-Ozbay and Ozbay, 2007) and overconfidence (Camerer and Lovallo, 1999; Park and Santos-Pinto, 2010). Although both of these factors are likely to add to the observed overbidding, no experimental study has systematically examined regret and overconfidence in relationship to behavior in contests. ${ }^{20}$ This is an interesting avenue for future research.

Based on the sample of contest experiments that we review, the median overbidding rate is $72 \%$. Moreover, in some studies the overbidding rate is so high that subjects on average earn

\footnotetext{
${ }^{20}$ Hyndman et al. (2012) study how regret aversion impacts individual behavior in all-pay auctions with incomplete information.
} 
negative payoffs. Given such high empirical rates of overbidding, it is imperative to develop and investigate different mechanisms that can reduce overbidding (i.e., conflict de-escalation) or maybe even prevent conflicts altogether (i.e., conflict resolution). We suggest several mechanisms in Section 4.6 through which overbidding can be reduced, including restricted distribution of pre-experimental endowments, communication, and social identity. We also suggest several conflict resolution mechanisms, such as side-payments and the use of randomization devices. The field of conflict resolution is very new and there are many interesting questions for future research pertaining to both conflict de-escalation and conflict resolution.

It is important to emphasize that overbidding in contests can also be used to increase economic welfare. In many applications, high contest expenditures may be viewed as preferable from the standpoint of the contest designer. For instance, in labor tournaments (Lazear and Rosen, 1981), effort is viewed as valuable because it contributes to the firm's output. In sports competitions (Szymanski, 2003), efforts have large positive externalities on fans and viewers. Similarly, in contests used to finance public goods (Morgan and Sefton, 2000) and raise money for charities (Landry et al., 2006), efforts provide significant positive externalities. Finally, overbidding in contests is good news for prize-linked savings mechanisms that use lottery contests to stimulate savings (Tufano, 2008).

Unlike overbidding, heterogeneous behavior of individuals is mostly viewed as negative, because such behavior creates unnecessary uncertainty and imposes a substantial cost on the contest designer (Bull et al., 1987; Lazear, 1999, 2000; Eriksson et al., 2009). In Sections 5.1-5.3 we provide explanations for heterogeneous behavior in contests based on (1) differences in preferences towards winning, inequality, risk and losses, and (2) demographic differences. There 
are other potential candidates to explain heterogeneous behavior of contestants that have not been explored yet. First, it is possible that there are different types in the population of subjects (for example see Herrmann and Orzen, 2008). Second, it is well documented that emotions are predictable and predictive of individual behavior in experimental games (Xiao and Houser, 2005; Schniter et al., 2011, 2013); therefore, individuals experiencing different emotions may exert different efforts in contests. Theoretically, we should expect individuals experiencing hate and revenge to exert higher effort (Amegashie and Runkel, 2012) and individuals experiencing guilt and shame to exert lower effort (Behrendt and Ben-Ari, 2012) in contests. Also, it is well documented that subjects have different personality traits, such as the Big Five personality characteristics (Kurzban and Houser, 2001; Borghans et al., 2008), and different cognitive abilities, as measured by IQ and SAT scores (Frey and Detterman, 2004). Future research should examine how these differences impact individual behavior in contests.

In Section 5.4 we discussed several mechanisms that can reduce heterogeneity of behavior that is due to subjects making mistakes in contests, such as group decision-making, feedback, and simplified payoff functions. The idea is that mechanisms that reduce cognitive load (Devetag and Warglien, 2003; Burks et al., 2009) and enhance subjects' learning of the contest environment should induce more homogeneous behavior. Given the potentially negative consequences of effort heterogeneity, future research should search for new mechanisms to induce more homogeneous behavior in contests.

On a more fundamental level, it is important to closely examine the main underlying factors that can explain individual behavior in contests. For example, although the factors contributing to the overbidding phenomenon (such as utility of winning, spite, status-seeking, mistakes, probability distortion, etc.) are frequently cited, it remains an open question as to 
whether some of these factors are correlated and if so, which are the most important ones. The overall impact of this correlation on individual and group behavior remains unknown. Similarly, probability distortion may be correlated with mistakes, risk-aversion, and loss-aversion; however, it is important to know which factors are the most important in explaining individual behavior in contests. The answers to these questions would significantly advance our understanding of the field. 


\section{References}

Abbink, K., Brandts, J., Herrmann, B. \& Orzen, H. (2010). Inter-Group Conflict and Intra-Group Punishment in an Experimental Contest Game. American Economic Review, 100, 420-447.

Agranov, M. \& Tergiman, C. (2013). Incentives and Compensation Schemes: An Experimental Study. International Journal of Industrial Organization, forthcoming.

Ahmed, A.M. (2009). Are religious people more prosocial? A quasi-experimental study with Madrasah pupils in a rural community in India. Journal for the Scientific Study of Religion, 48, 368-374.

Ahn, T.K., R, Isaac, M. \& Salmon, T.C. (2011). Rent Seeking in Groups. International Journal of Industrial Organization, 29, 116-125.

Amaldoss, W. \& Rapoport, A. (2009). Excessive Expenditure in Two-Stage Contests: Theory and Experimental Evidence. In F. Columbus (Ed.), Game Theory: Strategies, Equilibria, and Theorems. Hauppauge, NY: Nova Science Publishers.

Amegashie, J.A., \& Runkel, M. (2012). The Paradox of Revenge in Conflicts. Journal of Conflict Resolution, 56, 313-330.

Anderson, L.A. \& Stafford, S.L. (2003). An Experimental Analysis of Rent Seeking under Varying Competitive Conditions. Public Choice, 115, 199-216.

Andreoni, J. \& Croson, R., (2008). Partners versus strangers: the effect of random rematching in public goods experiments. In: Plott, C.R., Smith, V.L. (Eds.), Handbook of Experimental Economics Results, vol 1, North-Holland, Amsterdam; pp. 776-783.

Baharad, E. \& Nitzan, S. (2008). Contest Efforts in Light of Behavioural Considerations. Economic Journal, 118, 2047-2059.

Baik, K.H. (1994). Effort levels in contests with two asymmetric players. Southern Economic Journal, 61, 367-378.

Balafoutas, L. \& Sutter, M. (2012). Affirmative Action Policies Promote Women and do not Harm Efficiency in the Lab. Science, 335, 579-582.

Balafoutas, L., Kerschbamer, R. \& Sutter, M. (2012). Distributional Preferences and Competitive Behavior. Journal of Economic Behavior and Organization, 83, 125-135.

Bartling, B., Fehr, E., Marechal, M.A. \& Schunk, D. (2009). Egalitarianism and Competitiveness. American Economic Review, 99, 93-98.

Barut, Y. \& Kovenock, D. \& Noussair, C.N. (2002). A Comparison of Multiple-Unit All-Pay and Winner-Pay Auctions Under Incomplete Information. International Economic Review, 43, 675-708.

Batson, C., Schoenrade, P. \& Ventis, W. (1993). Religion and the individual: A SocialPsychological Perspective. New York: Oxford University Press.

Behrendt, H., \& Ben-Ari, R. (2012). The Positive Side of Negative Emotion: The Role of Guilt and Shame in Coping with Interpersonal Conflict. Journal of Conflict Resolution, 56, 11161138.

Benjamin, D.J., Choi, J.J. \& Fisher, G. (2012). Religious Identity and Economic Behavior. Working Paper.

Borghans, L., Duckworth, A.L., Heckman, J.J., \& Weel, B.T. (2008). The Economics and Psychology of Personality Traits. Journal of Human Resources, 43, 972-1059.

Botelho, A., Harrison, G.W., Pinto, L.M.C. \& Rutström, E.E. (2009). Testing static game theory with dynamic experiments: A case study of public goods. Games and Economic Behavior, 67, 253-265. 
Brookins, P. \& Ryvkin, D. (2011). An Experimental Study of Bidding in Contests of Incomplete Information. Working Paper.

Bull, C., Schotter, A. \& Weigelt, K. (1987). Tournaments and Piece Rates: an Experimental Study. Journal of Political Economy, 95, 1-33.

Burks, S.V., Carpenter, J.P., Gotte, L. \& Rustichini, A. (2009). Cognitive Skills Explain Economic Preferences, Strategic Behavior, and Job Attachment. Proceedings of the National Academy of Sciences, 106, 7745-7750.

Camerer, C.F. \& Lovallo, D. (1999). Overconfidence and Excess Entry: An Experimental Approach. American Economic Review, 89, 306-18.

Casari, M., Ham, J.C. \& Kagel, J.H. (2007). Selection Bias, Demographic Effects, and Ability Effects in Common Value Auction Experiments. American Economic Review, 97, 12781304.

Cason, T.N., Masters, W.A. \& Sheremeta, R.M. (2010). Entry into Winner-Take-All and Proportional-Prize Contests: An Experimental Study. Journal of Public Economics, 94, 604611.

Cason, T.N., Masters, W.A. \& Sheremeta, R.M. (2011). Winner-Take-All and Proportional-Prize Contests: Theory and Experimental Results. Chapman University, ESI Working Paper.

Cason, T.N., Sheremeta, R.M. \& Zhang, J. (2012). Communication and Efficiency in Competitive Coordination Games. Games and Economic Behavior, 76, 26-43.

Charness, G. \& Sutter, M. (2012). Groups Make Better Self-Interested Decisions. Journal of Economic Perspectives, 26, 157-76.

Chau, A. \& Phillips, J. (1995). Effects of Perceived Control Upon Wagering and Attributions in Computer Blackjack. Journal of General Psychology, 122, 253-269.

Chen, Y., Katuscak, P. \& Ozdenoren, E. (2013). Why Can't a Woman Bid More Like a Man? Games and Economic Behavior, 77, 181-213.

Chowdhury, S.M. \& Sheremeta, R.M. (2011). Multiple Equilibria in Tullock Contests. Economics Letters, 112, 216-219.

Chowdhury, S.M., Kovenock, D. \& Sheremeta, R.M. (2013). An Experimental Investigation of Colonel Blotto Games. Economic Theory, forthcoming.

Chowdhury, S.M., Sheremeta, R.M., Turocy, T.L. (2012). Overdissipation and Convergence in Rent-Seeking Experiments: Cost Structure and Prize Allocation Rules. Chapman University, ESI Working Paper.

Cornes, R. \& Hartley, R. (2012). Loss Aversion in Contests. Working Paper.

Croson, R. \& Sundali, J. (2005). The Gambler's Fallacy and the Hot Hand: Empirical Data from Casinos. Journal of Risk and Uncertainty, 30, 195-209.

Davis, D. \& Reilly, R. (1998). Do Many Cooks Always Spoil the Stew? An Experimental Analysis of Rent Seeking and The Role of A Strategic Buyer. Public Choice, 95, 89-115.

Dechenaux, E. \& Mancini, M. (2008). Auction-Theoretic Approach to Modeling Legal Systems: An Experimental Analysis. Applied Economics Research Bulletin, 2, 142-177.

Dechenaux, E., Kovenock, D. \& Sheremeta, R.M. (2012). A Survey of Experimental Research on Contests, All-Pay Auctions and Tournaments. Chapman University, ESI Working Paper.

Deck, C. \& Jahedi, S. (2011). Time Discounting in Strategic Contests. Working Paper.

Deck, C. \& Sheremeta, R.M. (2012). Fight or Flight? Defending Against Sequential Attacks in the Game of Siege. Journal of Conflict Resolution, 56, 1069-1088. 
Delgado, M.R., Schotter, A., Ozbay, E.Y., \& Phelps, E.A. (2008). Understanding Overbidding: Using the Neural Circuitry of Reward to Design Economic Auctions. Science, 321, 18491852.

Devetag, G. \& Warglien, M. (2003). Games and phone numbers: Do short-term memory bounds affect strategic behavior? Journal of Economic Psychology, 24, 189-202.

Eisenkopf, G. \& Teyssier, S. (2013). Envy and Loss Aversion in Tournaments. Journal of Economic Psychology, forthcoming.

Engelbrecht-Wiggans, R. \& Katok, E. (2007). Regret in auctions: Theory and evidence. Economic Theory, 33, 81-101.

Ericsson, K.A. \& Charness, N. (1994). Expert performance: Its structure and acquisition. American Psychologist, 49, 725 - 747.

Eriksson, T., Teyssier, S. \& Villeval, M.C. (2009). Self-Selection and The Efficiency of Tournaments. Economic Inquiry, 47, 530-548.

Fallucchi, F., Renner, E. \& Sefton, M. (2012). Information feedback and contest structure in rent-seeking games. Working Paper.

Faravelli, M. \& Stanca, L. (2012). When Less is More: Rationing and Rent Dissipation in Stochastic Contests. Games and Economic Behavior, 74, 170-183.

Filiz-Ozbay, E., Ozbay, E.Y. (2007). Auctions with anticipated regret: Theory and experiment. American Economic Review, 97, 1407-1418.

Fonseca, M.A. (2009). An Experimental Investigation of Asymmetric Contests. International Journal of Industrial Organization, 27, 582-591.

Frey, M.C., \& Detterman, D.K. (2004). Scholastic Assessment or g?: The Relationship Between the Scholastic Assessment Test and General Cognition Ability. Psychological Science, 15, 73- 378.

Gill, D. \& Prowse, V. (2012). A Structural Analysis of Disappointment Aversion in a Real Effort Competition. American Economic Review, 102, 469-503.

Gill, D. \& Stone, R., (2010). Fairness and desert in tournaments. Games and Economic Behavior, 69, 346-364.

Gilovich, T., Vallone, R. \& Tversky, A. (1985). The Hot Hand in Basketball: On the Misperception of Random Sequences. Cognitive Psychology, 17, 295-314.

Gneezy, U. \& Smorodinsky, R. (2006). All-Pay Auctions - An Experimental Study. Journal of Economic Behavior and Organization, 61, 255-275.

Ham, J.C. \& Kagel, J.H. (2006). Gender Effects in Private Value Auctions. Economic Letters, 92, 375-382.

Hamilton, W. D. (1970). Selfish and spiteful behavior in evolutionary model. Nature, 228, 12181220.

Harbring, C. \& Irlenbusch, B. (2011). Sabotage in Tournaments: Evidence from a Laboratory Experiment. Management Science, 57, 611-627.

Hehenkamp, B., Leininger, W. \& Possajenikov, A. (2004). Evolutionary equilibrium in Tullock contests: spite and overdissipation. European Journal of Political Economy, 20, 1045-1057.

Herrmann, B. \& Orzen, H. (2008). The Appearance of Homo Rivalis: Social Preferences and the Nature of Rent Seeking. University of Nottingham, Working Paper.

Hilary, G. \& Hui, K.W. (2009). Does Religion Matter in Corporate Decision Making in America? Journal of Financial Economics, 93, 455-473.

Hillman, A. \& Riley, J.G. (1989). Politically contestable rents and transfers. Economics and Politics, 1, 17-40. 
Hillman, A.L. \& Katz, E. (1984). Risk-Averse Rent Seekers and the Social Cost of Monopoly Power. Economic Journal, 94, 104-110.

Hirshleifer, J. \& Riley, J.G. (1978). Elements of the Theory of Auctions and Contests. UCLA Economics Working Papers 118.

Holt, C.A. \& Laury, S.K. (2002). Risk Aversion and Incentive Effects. American Economic Review, 92, 1644-1655.

Hyndman, K., Ozbay, E.Y. \& Sujarittanonta, P. (2012). Rent Seeking with Regretful Agents: Theory and Experiment. Journal of Economic Behavior and Organization, 84, 866-878.

Kahneman, D. \& Tversky, A. (1979). Prospect theory: an analysis of decision under risk, Econometrica, 47, 263-91.

Kahneman, D., Knetsch, J.L. \& Thaler, R.H. (1990). Experimental Tests of the Endowment Effect and the Coase Theorem. Journal of Political Economy, 98, 1325-1348.

Ke, C., Konrad, K.A. \& Morath, F. (2013). Brothers in Arms - An Experiment on the Alliance Puzzle. Games and Economic Behavior, 77, 61-76.

Kimbrough, E.O. \& Sheremeta, R.M. (2012). Why Can't We Be Friends? Entitlements and the Costs of Conflict. Chapman University, ESI Working Paper.

Kimbrough, E.O. \& Sheremeta, R.M. (2013). Side-Payments and the Costs of Conflict. International Journal of Industrial Organization, forthcoming.

Kimbrough, E.O., Rubin, J., Sheremeta, R.M. \& Shields, T. (2013). Coordination, Commitment and Conflict Resolution. Chapman University, ESI Working Paper.

Kimbrough, E.O., Sheremeta, R.M. \& Shields, T. (2011). Resolving Conflicts by a Random Device. Chapman University, ESI Working Paper.

Klemperer, P. (2002). How (Not) to Run Auctions: The European 3G Telecom Auctions. European Economic Review, 46, 829-845.

Klose, B. \& Sheremeta, R.M. (2012). Behavior in All-Pay and Winner-Pay Auctions with Identity-Dependent Externalities. Working Paper.

Kong, X. (2008). Loss Aversion and Rent-Seeking: An Experimental Study. University of Nottingham, Working Paper.

Konrad, K. A. and Schlesinger, H. (1997). Risk Aversion in Rent-Seeking and Rent-Augmenting Games. Economic Journal, 107, 1671-1683.

Konrad, K.A. (2009). Strategy and Dynamics in Contests. New York, NY: Oxford University Press.

Kovenock, D., Roberson, B. \& Sheremeta, R.M. (2010). The Attack and Defense of WeakestLink Networks. Chapman University, ESI Working Paper.

Kurzban, R., \& Houser, D. (2001). Individual Differences in Cooperation in a Circular Public Goods Game. European Journal of Personality, 15, 37-52.

Landry, C., Lange, A., List, J.A., Price, M.K. \& Rupp, N. (2006). Toward an Understanding of the Economics of Charity: Evidence from a Field Experiment. Quarterly Journal of Economics, 121, 747-782.

Lazear, E.P. \& Rosen, S. (1981). Rank-Order Tournaments as Optimum Labor Contracts. Journal of Political Economy, 89, 841-864.

Lazear, E.P. (1999). Personnel economics past lessons and future directions - presidential address to the society of labor economists. Journal of Labor Economics, 17, 199-236.

Lazear, E.P. (2000). Performance pay and productivity. American Economic Review, 90, 13461361. 
Leininger, W. (2003). On evolutionarily stable behavior in contests. Economics of Governance, 4, 177-186.

Lim, W., Matros, A. \& Turocy, T. (2012). Bounded rationality and group size in Tullock contests: Experimental evidence. Working Paper.

Lugovskyy, V., Puzzello, D. \& Tucker, S. (2010). An Experimental Investigation of Overdissipation in the All Pay Auction. European Economic Review, 54, 974-997.

Mago, S.D. \& Sheremeta, R.M. (2012). Multi-Battle Contests: An Experimental Study. Chapman University, ESI Working Paper.

Mago, S.D., Savikhin, A.C. \& Sheremeta, R.M. (2012). Facing Your Opponents: Social Identification and Information Feedback in Contests. Chapman University, ESI Working Paper.

Mago, S.D., Sheremeta, R.M. \& Yates, A. (2013). Best-of-Three Contest Experiments: Strategic Versus Psychological Momentum. International Journal of Industrial Organization, forthcoming.

Masiliunas, A., Mengel, F. Reiss, J.P. (2012). (Strategic) Uncertainty and the Explanatory Power of Nash Equilibrium in Tullock Contests. Working Paper.

McKelvey, R. \& Palfrey, T. (1995). Quantal Response Equilibria for Normal Form Games. Games and Economic Behavior, 10, 6-38.

Millner, E.L. \& Pratt, M.D. (1989). An Experimental Investigation of Efficient Rent-Seeking. Public Choice, 62, 139-151.

Millner, E.L. \& Pratt, M.D. (1991). Risk Aversion and Rent-Seeking: An Extension and Some Experimental Evidence. Public Choice, 69, 81-92.

Minor, D. (2012). Coarse Thinking and Competition. Working Paper.

Morgan, J. \& Sefton, M. (2000). Funding Public Goods with Lotteries: Experimental Evidence. Review of Economic Studies, 67, 785-810.

Morgan, J., Orzen, H. \& Sefton, M. (2012). Endogenous Entry in Contests. Economic Theory, 51, 435-463.

Müller, W. \& Schotter, A. (2010). Workaholics and Dropouts in Organizations. Journal of the European Economic Association, 8, 717-743.

Nalebuff, B.J. \& Stiglitz, J.E. (1982). Prizes and Incentives: Towards a General Theory of Compensation and Competition. Bell Journal of Economics, 13, 21-43.

Niederle, M. \& Vesterlund, L. (2007). Do Women Shy Away from Competition? Do Men Compete Too Much? Quarterly Journal of Economics, 122, 1067-1101.

Noussair, C. \& Silver, J. (2006). Behavior in All Pay Auctions with Incomplete Information. Games and Economic Behavior, 55, 189-206.

Parco J., Rapoport A. \& Amaldoss W. (2005). Two-Stage Contests with Budget Constraints: An Experimental Study. Journal of Mathematical Psychology, 49, 320-338.

Park, Y.J. \& Santos-Pinto, L. (2010). Overconfidence in Tournaments: Evidence from the Field. Theory and Decision, 69, 143-166.

Potters, J.C., De Vries, C.G. \& Van Winden, F. (1998). An Experimental Examination of Rational Rent Seeking. European Journal of Political Economy, 14, 783-800.

Prendergast, C. (1999). The Provision of Incentives in Firms. Journal of Economic Literature, 37, 7-63.

Price, C.R. \& Sheremeta, R.M. (2011). Endowment Effects in Contests. Economics Letters, 111, 217-219. 
Price, C.R. \& Sheremeta, R.M. (2012). Endowment Origin, Demographic Effects and Individual Preferences in Contests. Chapman University, ESI Working Paper.

Price, C.R. (2012). Gender, Competition, and Managerial Decisions. Management Science, 58, 114-122.

Regnerus, M., Smith, C. \& Sikkink, D. (1998). Who gives to the poor? The influence of religious tradition and political location on the personal generosity of Americans toward the poor. Journal for the Scientific Study of Religion, 37, 481-493.

Riechmann, T. (2007). An analysis of rent-seeking games with relative-payoff maximizers. Public Choice, 133, 147-155.

Savikhin, A.C. \& Sheremeta, R.M. (2013). Simultaneous Decision-Making in Competitive and Cooperative Games. Economic Inquiry, forthcoming.

Schmidt, D., Sheremeta, R.M., Shupp, R. \& Walker, J. (2005). Resource Allocation Contests: Experimental Evidence. Indiana University, Working Paper.

Schmitt, P., Shupp, R., Swope, K. \& Cadigan, J. (2004). Multi-Period Rent-Seeking Contests with Carryover: Theory and Experimental Evidence. Economics of Governance, 5, 187-211.

Schniter, E., Sheremeta, R.M., \& Shields, T. (2011). Conflicted Minds: Recalibrational Emotions Following Trust-based Interaction. Chapman University, ESI Working Papers.

Schniter, E., Sheremeta, R.M., \& Sznycer, D. (2013). Building and Rebuilding Trust with Promises and Apologies. Journal of Economic Behavior and Organization, forthcoming.

Schotter, A. \& Weigelt, K. (1992). Asymmetric Tournaments, Equal Opportunity Laws, and Affirmative Action: Some Experimental Results. Quarterly Journal of Economics, 107, 511539.

Sheremeta, R.M. \& Wu, S.Y. (2011). Optimal Tournament Design and Incentive Response: An Experimental Investigation of Canonical Tournament Theory. Chapman University, ESI Working Paper.

Sheremeta, R.M. \& Zhang, J. (2010). Can Groups Solve the Problem of Over-Bidding in Contests? Social Choice and Welfare, 35, 175-197.

Sheremeta, R.M. (2010). Experimental Comparison of Multi-Stage and One-Stage Contests. Games and Economic Behavior, 68, 731-747.

Sheremeta, R.M. (2011). Contest Design: An Experimental Investigation. Economic Inquiry, 49, 573-590.

Shogren, J.F. \& Baik, K.H. (1991). Reexamining Efficient Rent-Seeking in Laboratory Markets. Public Choice, 69, 69-79.

Skaperdas, S. \& Gan, L. (1995). Risk Aversion in Contests. Economic Journal, 105, 951-62.

Stein, W. (2002). Asymmetric Rent-Seeking with More Than Two Contestants. Public Choice, $113,325-336$.

Szidarovszky, F., Okuguchi, K., (1997). On the existence and uniqueness of pure Nash equilibrium in rent-Seeking games. Games and Economic Behavior 18, 135-140.

Szymanski, S. (2003). The economic design of sporting contests. Journal of Economic Literature, 41, 1137-1187.

Tufano, P. (2008). Saving whilst Gambling: An Empirical Analysis of UK Premium Bonds. American Economic Review, 98, 321-326.

Tullock, G. (1980). Efficient Rent Seeking. In James M. Buchanan, Robert D. Tollison, Gordon Tullock, (Eds.), Toward a theory of the rent-seeking society. College Station, TX: Texas A\&M University Press, pp. 97-112. 
Tversky, A. \& Kahneman, D. (1992). Advances in Prospect Theory: Cumulative Representation of Uncertainty. Journal of Risk and Uncertainty, 5, 297-323.

Xiao, E., \& Houser, D. (2005). Emotion expression in human punishment behavior. Proceedings of the National Academy of Sciences of the United States of America, 102, 7398-7401.

Zizzo, D. (2010). Experimenter demand effects in economic experiments. Experimental Economics, 13, 75-98. 
Figure 1: Endowment and the Expected Average Effort at the QRE.

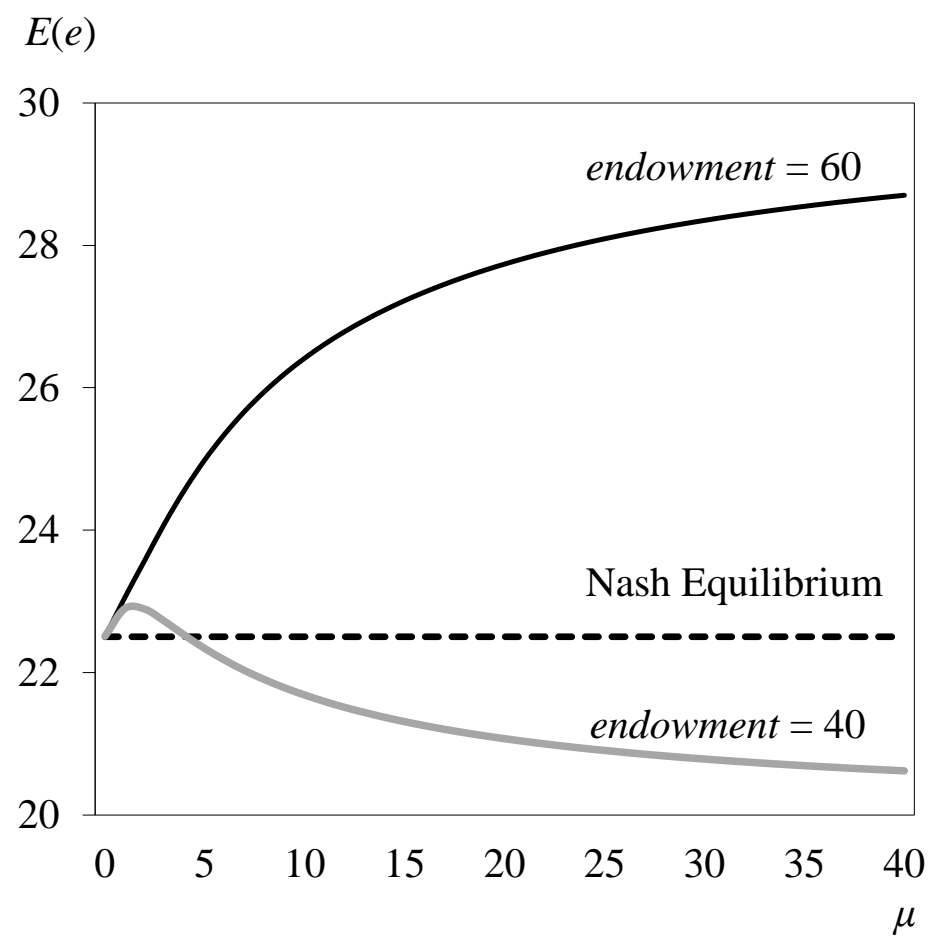

Figure 2: Utility of Winning.

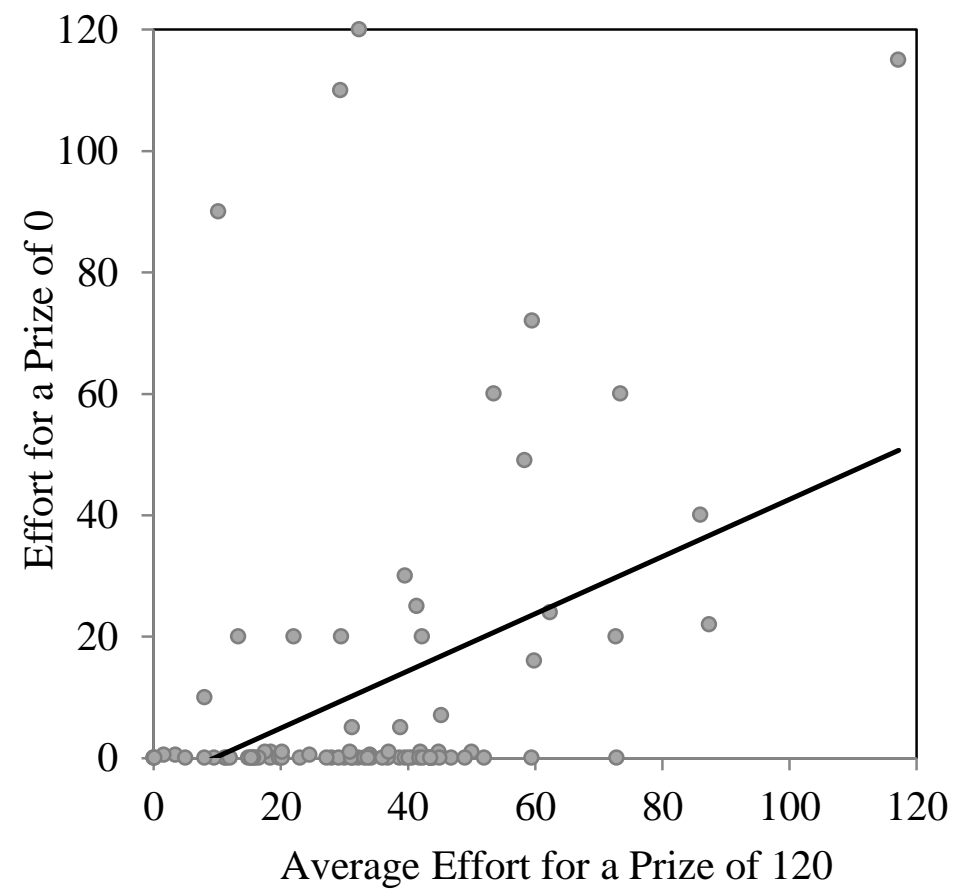

Note: The data are taken from Sheremeta (2010). 
Figure 3: Probability Distortion.

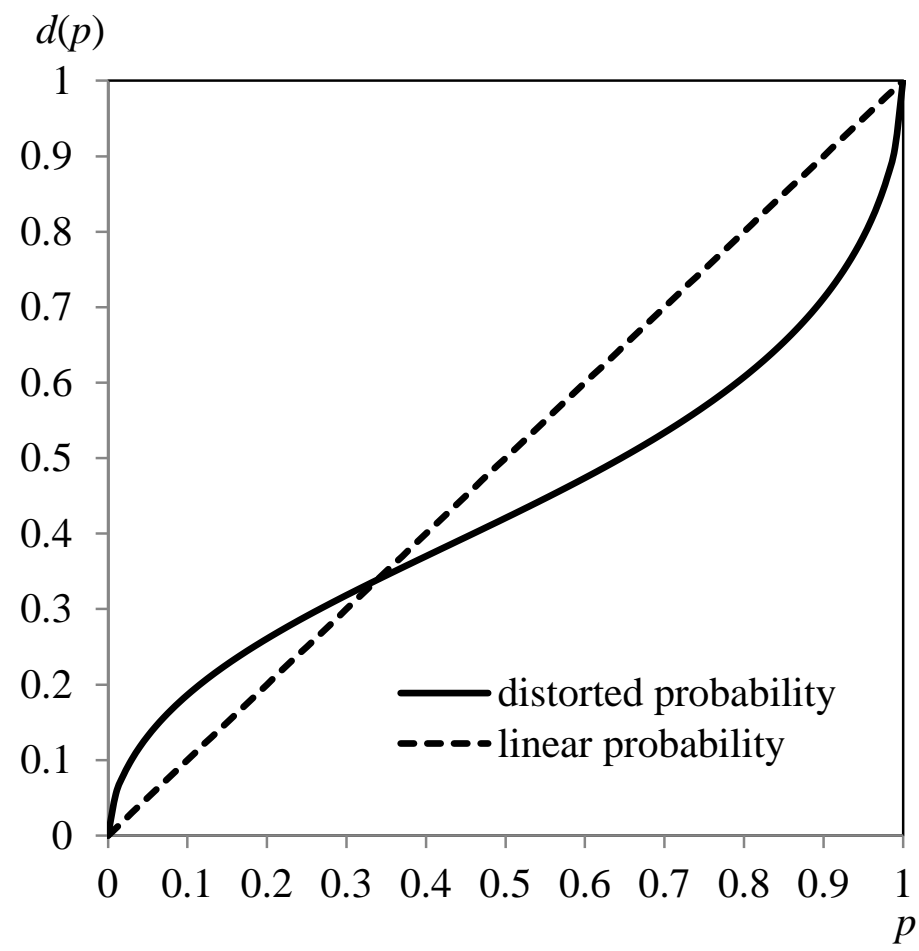

Figure 4: Linear versus Convex Costs.

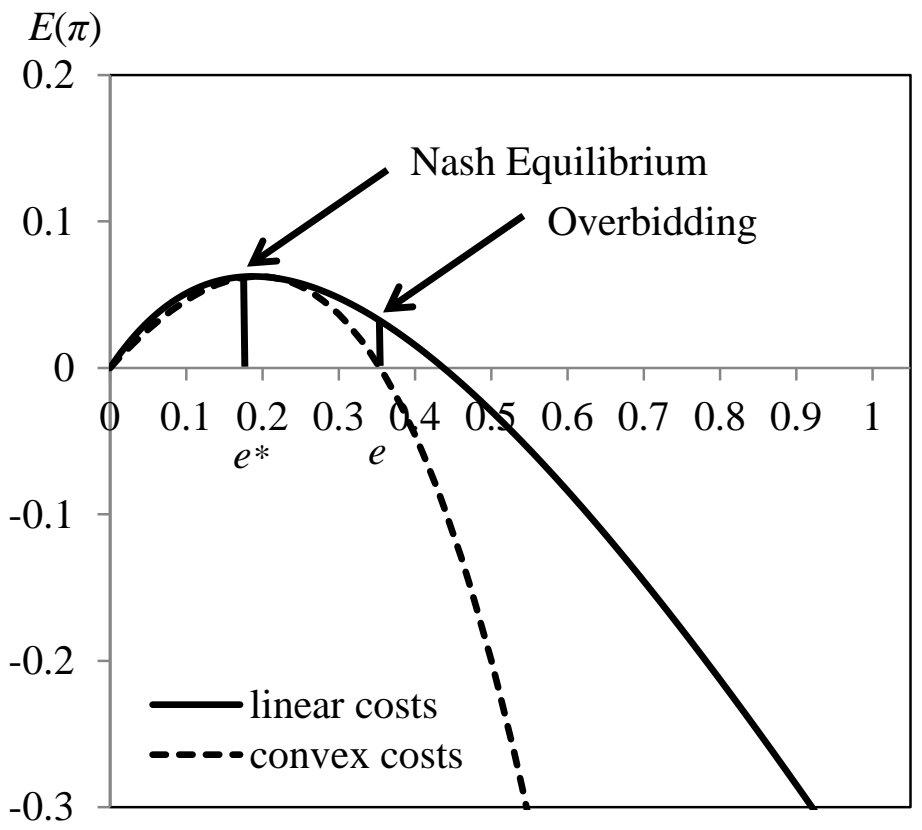


Figure 5: Distribution of Efforts in a Lottery Contest.

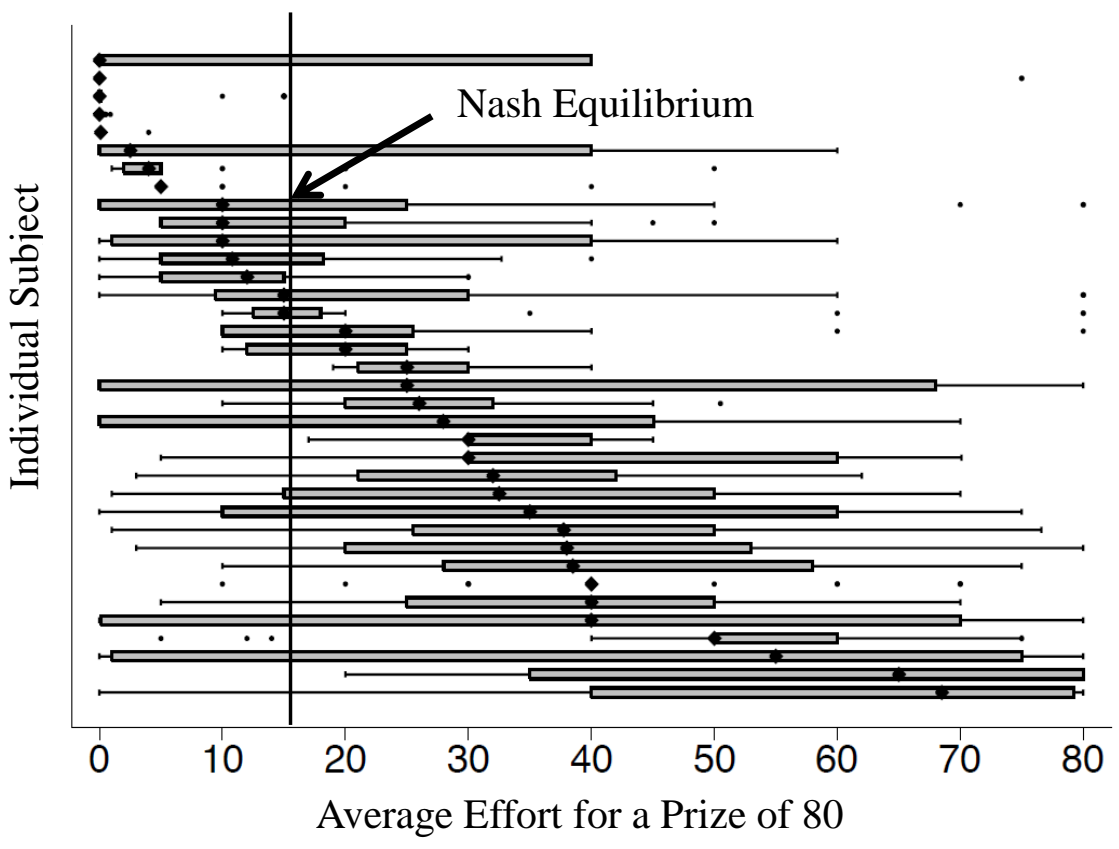

Note: The data are taken from Chowdhury et al. (2012).

Figure 6: Average Effort by Gender.

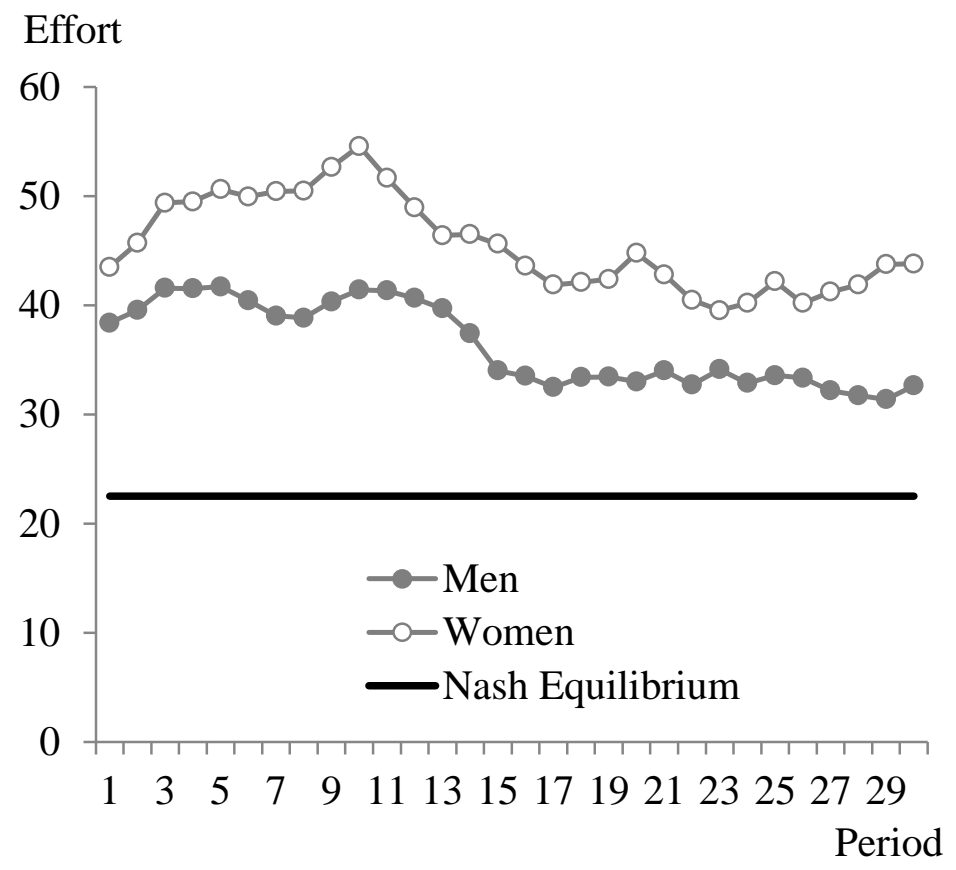

Note: The data are taken from Price and Sheremeta (2012). 
Figure 7: Average Effort by Religiosity.

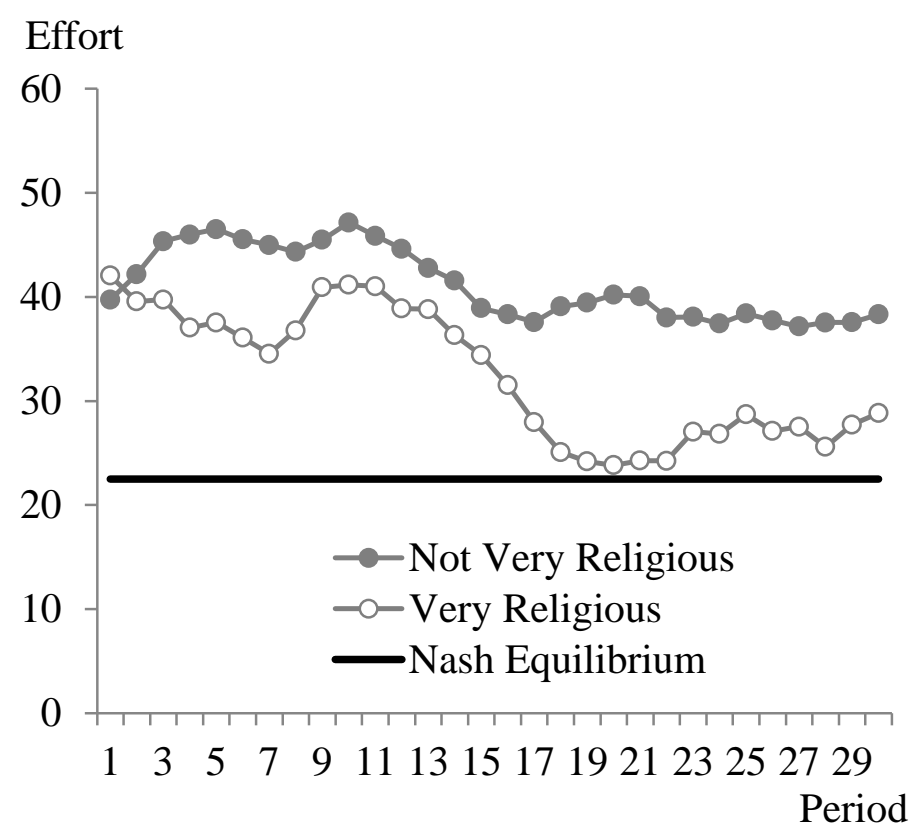

Note: The data are taken from Price and Sheremeta (2012).

Figure 8: Average Effort over 20 Periods of Experiment.

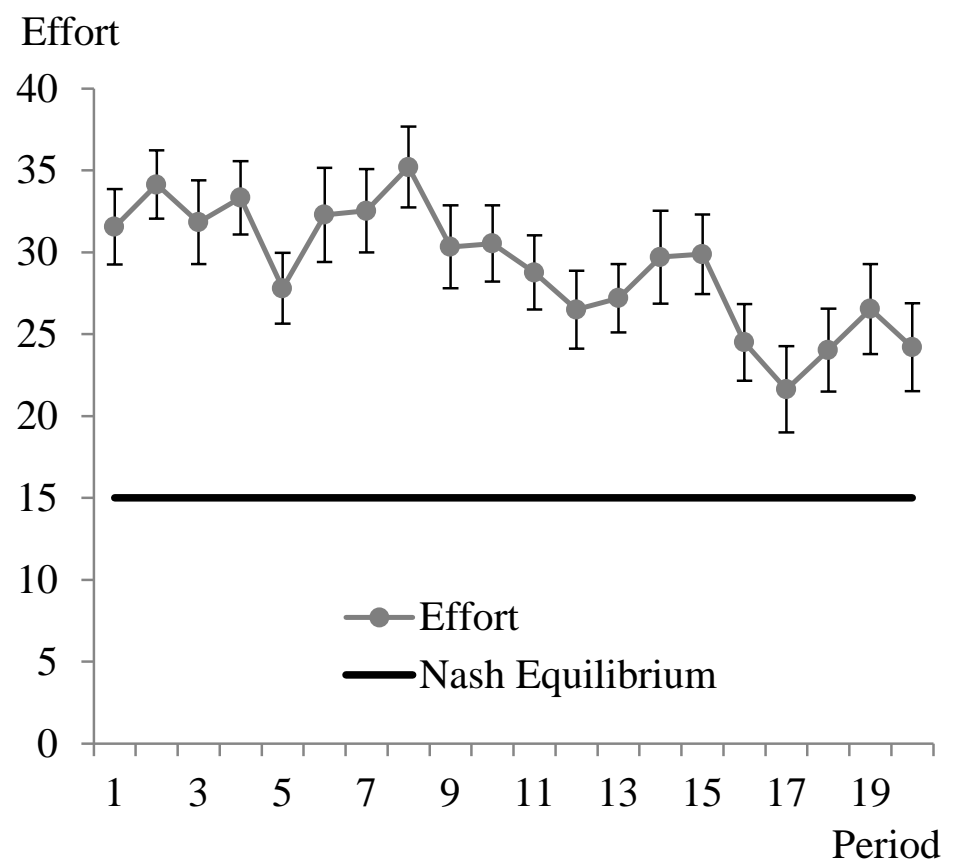

Note: The data are taken from Mago et al. (2012). 
Table 1: Summary of Lottery Contest Experiments.

\begin{tabular}{|c|c|c|c|c|c|c|c|c|c|}
\hline Study & Year & Treatment Name & Matching & Endowment & $\begin{array}{c}\text { Prize } \\
\text { value } \\
v\end{array}$ & $\begin{array}{c}\text { Number of } \\
\text { players } \\
n\end{array}$ & $\begin{array}{c}\text { Predicted } \\
\text { effort } \\
e^{*}\end{array}$ & $\begin{array}{c}\text { Actual } \\
\text { effort } \\
e\end{array}$ & $\begin{array}{c}\text { Overbidding } \\
\text { rate } \\
\left(e-e^{*}\right) / e^{*}\end{array}$ \\
\hline Millner and Pratt & 1989 & Lottery & Random & 12 & 8 & 2 & 2.00 & 2.24 & $12 \%$ \\
\hline Millner and Pratt & 1991 & Less risk-averse & Random & 12 & 8 & 2 & 2.00 & 2.45 & $23 \%$ \\
\hline Shogren and Baik & 1991 & Lottery & Fixed & 24 & 32 & 2 & 8.00 & 8.11 & $1 \%$ \\
\hline Davis and Reilly & 1998 & Lottery & Fixed & Cash balance & 200 & 4 & 37.50 & 54.97 & $46 \%$ \\
\hline Potters et al. & 1998 & Lottery & Random & 15 & 12 & 2 & 3.00 & 5.05 & $68 \%$ \\
\hline \multirow[t]{5}{*}{ Anderson and Stafford } & 2003 & Homogeneous & One shot & 5 & 5 & 2 & 1.25 & 2.42 & $94 \%$ \\
\hline & & & One shot & 5 & 5 & 3 & 1.11 & 2.00 & $80 \%$ \\
\hline & & & One shot & 5 & 5 & 4 & 0.94 & 2.25 & $139 \%$ \\
\hline & & & One shot & 5 & 5 & 5 & 0.80 & 2.85 & $256 \%$ \\
\hline & & & One shot & 5 & 5 & 10 & 0.45 & 1.33 & $196 \%$ \\
\hline Schmitt et al. & 2004 & Static & Random & 150 & 120 & 2 & 30.00 & 52.70 & $76 \%$ \\
\hline Schmidt et al. & 2005 & Single-prize & One shot & 20 & 72 & 4 & 13.5 & 9.4 & $-30 \%$ \\
\hline Herrmann and Orzen & 2008 & Direct repeated & Random & 16 & 16 & 2 & 4.00 & 8.20 & $105 \%$ \\
\hline Kong & 2008 & Less loss averse & Fixed & 300 & 200 & 3 & 44.44 & 80.56 & $81 \%$ \\
\hline Fonseca & 2009 & Simultaneous & Random & 300 & 200 & 2 & 50.00 & 100.08 & $100 \%$ \\
\hline Abbink et al. & 2010 & $1: 1$ & Fixed & 1000 & 1000 & 2 & 250 & 513 & $105 \%$ \\
\hline Sheremeta & 2010 & One-Stage & Random & 120 & 120 & 4 & 22.5 & 34.1 & $52 \%$ \\
\hline Sheremeta and Zhang & 2010 & Individual & Random & 120 & 120 & 4 & 22.5 & 43.8 & $95 \%$ \\
\hline Ahn et al. & 2011 & Individual & Fixed & Cash balance & 1000 & 2 & 250 & 342.5 & $37 \%$ \\
\hline Deck and Jahedi & 2011 & Baseline & One shot & 5 & 5 & 2 & 1.25 & 2.05 & $64 \%$ \\
\hline Price and Sheremeta & 2011 & $\mathrm{P}$ treatment & Random & 120 & 120 & 4 & 22.5 & 42.8 & $90 \%$ \\
\hline \multirow[t]{2}{*}{ Sheremeta } & 2011 & GC & Random & 60 & 120 & 4 & 22.5 & 30.0 & $33 \%$ \\
\hline & & SC & Random & 60 & 60 & 2 & 15.0 & 19.7 & $31 \%$ \\
\hline Cason et al. & 2012 & Individual & Fixed & 60 & 60 & 2 & 15.0 & 18.96 & $26 \%$ \\
\hline Chowdhury et al. & 2012 & PL & Random & 80 & 80 & 4 & 15.0 & 26.2 & $75 \%$ \\
\hline Fallucchi et al. & 2012 & Own-Stochastic & Fixed & 1000 & 1000 & 3 & 222 & 368.5 & $66 \%$ \\
\hline Faravelli and Stanca & 2012 & LOT & Random & 800 & 1600 & 2 & 400 & 440.8 & $10 \%$ \\
\hline \multirow[t]{3}{*}{ Lim et al. } & 2012 & $\mathrm{~N}=2$ & Random & 1200 & 1000 & 2 & 250 & 325 & $30 \%$ \\
\hline & & $\mathrm{N}=4$ & Random & 1200 & 1000 & 4 & 187.5 & 302 & $61 \%$ \\
\hline & & $\mathrm{N}=9$ & Random & 1200 & 1000 & 9 & 98.8 & 326 & $230 \%$ \\
\hline Mago et al. & 2012 & NPNI & Fixed & 80 & 80 & 4 & 15.0 & 29.1 & $94 \%$ \\
\hline Masiliunasy et al. & 2012 & N1S1 & Random & 16 & 16 & 2 & 4.00 & 4.98 & $25 \%$ \\
\hline \multirow[t]{3}{*}{ Morgan et al. } & 2012 & Small prize & Fixed & 100 & 50 & 2 & 12.5 & 21.5 & $72 \%$ \\
\hline & & & Fixed & 100 & 50 & 3 & 11.1 & 16.1 & $45 \%$ \\
\hline & & & Fixed & 100 & 50 & 4 & 9.4 & 21.7 & $131 \%$ \\
\hline Price and Sheremeta & 2012 & Gift & Random & 120 & 120 & 4 & 22.5 & 43.2 & $92 \%$ \\
\hline Ke et al. & 2013 & Baseline & Random & 250 & 450 & 3 & 100 & 150 & $50 \%$ \\
\hline Kimbrough and Sheremeta & 2013 & Baseline & Random & 60 & 60 & 2 & 15.0 & 29.3 & $95 \%$ \\
\hline Savikhin and Sheremeta & 2013 & Baseline & Fixed & 80 & 80 & 4 & 15.0 & 33.5 & $123 \%$ \\
\hline
\end{tabular}


2013

\section{Economic Science Institute Working Papers}

13-05 Deck, C. and Porter, D. Prediction Markets in the Laboratory.

13-04 Corgnet, B., Hernán-Gonzalez, R., Kujal, P., and Porter, D. The Effect of Earned vs. House Money on Price Bubble Formation in Experimental Asset Markets.

13-03 Sheremeta, R. and Zhang, J. Three-Player Trust Game with Insider Communication.

13-02 McCarter, M. and Sheremeta, R. You Can't Put Old Wine in New Bottles: The Effect of Newcomers on Coordination in Groups.

13-01 Corgnet, B., Hernan-Gonzalez, R., and Rassenti, S. Peer Pressure and Moral Hazard in Teams: Experimental Evidence.

2012

12-31 Thomas, C. An Alternating-Offers Model of Multilateral Negotiations.

12-30 Mago, S., Sheremeta, R. and Yates, A. Best-of-Three Contest Experiments: Strategic versus psychological momentum.

12-29 Bigoni, M., Camera, G. and Casari, M. Strategies of Cooperation and Punishment among Students and Clerical Workers.

12-28 Camera, G. and Kim, J. Buyer's Equilibrium with Capacity Constraints and Restricted Mobility: A recursive approach.

12-27 Camera, G., Casari, M., and Bigoni, M. Binding Promises and Cooperation Among Strangers.

12-26 Schniter, E., Shields, T. and Dickhaut, J. Ageism \& Cooperation.

12-25 Gjerstad, S. and Smith, V. Balance Sheet Crises: Causes, Consequences and Responses.

12-24 Gómez-Miñambres, J., Corgnet, B. and Hernán-Gonzalez, R. Goal Setting and Monetary Incentives: When Large Stakes Are Not Enough.

12-23 Clots-Figueras, I., Hernán González, R., and Kujal, P. Asymmetry and Deception in the Investment Game.

12-22 Dechenaux, E., Kovenock, D. and Sheremeta, R. A Survey of Experimental Research on Contests, All-Pay Auctions and Tournaments. 
12-21 Rubin, J. and Sheremeta, R. Principal-Agent Settings with Random Shocks.

12-20 Gómez-Miñambres, J. and Schniter, E. Menu-Dependent Emotions and Self-Control.

12-19 Schniter, E., Sheremeta, R., and Sznycer, D. Building and Rebuilding Trust with Promises and Apologies.

12-18 Shields, T. and Xin, B. Higher-order Beliefs in Simple Trading Models.

12-17 Pfeiffer, G. and Shields, T. Performance-Based Compensation and Firm Value: Experimental evidence.

12-16 Kimbrough, E. and Sheremeta, R. Why Can't We Be Friends? Entitlements, bargaining, and conflict.

12-15 Mago, S., Savikhin, A., and Sheremeta, R. Facing Your Opponents: Social identification and information feedback in contests.

12-14 McCarter, M., Kopelman, S., Turk, T. and Ybarra, C. Too Many Cooks Spoil the Broth: How the tragedy of the anticommons emerges in organizations.

12-13 Chowdhury, S., Sheremeta, R. and Turocy, T. Overdissipation and Convergence in Rent-seeking Experiments: Cost structure and prize allocation rules.

12-12 Bodsky, R., Donato, D., James, K. and Porter, D. Experimental Evidence on the Properties of the California's Cap and Trade Price Containment Reserve.

12-11 Branas-Garza, P., Espin, A. and Exadaktylos, F. Students, Volunteers and Subjects: Experiments on social preferences.

12-10 Klose, B. and Kovenock, D. Extremism Drives Out Moderation.

12-09 Buchanan, J. and Wilson, B. An Experiment on Protecting Intellectual Property.

12-08 Buchanan, J., Gjerstad, S. and Porter, D. Information Effects in Multi-Unit Dutch Auctions.

12-07 Price, C. and Sheremeta, R. Endowment Origin, Demographic Effects and Individual Preferences in Contests.

12-06 Magoa, S. and Sheremeta, R. Multi-Battle Contests: An experimental study.

12-05 Sheremeta, R. and Shields, T. Do Liars Believe? Beliefs and Other-Regarding Preferences in Sender-Receiver Games.

12-04 Sheremeta, R., Masters, W. and Cason. T. Winner-Take-All and Proportional-Prize Contests: Theory and experimental results.

12-03 Buchanan, J., Gjerstad, S. and Smith, V. There's No Place Like Home. 
12-02 Corgnet, B. and Rodriguez-Lara, I. Are you a Good Employee or Simply a Good Guy? Influence Costs and Contract Design.

12-01 Kimbrough, E. and Sheremeta, R. Side-Payments and the Costs of Conflict.

\section{1}

11-20 Cason, T., Savikhin, A. and Sheremeta, R. Behavioral Spillovers in Coordination Games.

11-19 Munro, D. and Rassenti, S. Combinatorial Clock Auctions: Price direction and performance.

11-18 Schniter, E., Sheremeta, R., and Sznycer, D. Restoring Damaged Trust with Promises, Atonement and Apology.

11-17 Brañas-Garza, P., and Proestakis, A. Self-discrimination: A field experiment on obesity.

11-16 Brañas-Garza, P., Bucheli, M., Paz Espinosa, M., and García-Muñoz, T. Moral Cleansing and Moral Licenses: Experimental evidence.

11-15 Caginalp, G., Porter, D., and Hao, L. Asset Market Reactions to News: An experimental study.

11-14 Benito, J., Branas-Garz, P., Penelope Hernandez, P., and Sanchis Llopis, J. Strategic Behavior in Schelling Dynamics: A new result and experimental evidence.

11-13 Chui, M., Porter, D., Rassenti, S. and Smith, V. The Effect of Bidding Information in Ascending Auctions.

11-12 Schniter, E., Sheremeta, R. and Shields, T. Conflicted Minds: Recalibrational emotions following trust-based interaction.

11-11 Pedro Rey-Biel, P., Sheremeta, R. and Uler, N. (Bad) Luck or (Lack of) Effort?: Comparing social sharing norms between US and Europe.

11-10 Deck, C., Porter, D., and Smith, V. Double Bubbles in Assets Markets with Multiple Generations.

11-09 Kimbrough, E., Sheremeta, R., and Shields, T. Resolving Conflicts by a Random Device.

11-08 Brañas-Garza, P., García-Muñoz, T., and Hernan, R. Cognitive effort in the Beauty Contest Game.

11-07 Grether, D., Porter, D., and Shum, M. Intimidation or Impatience? Jump Bidding in On-line Ascending Automobile Auctions.

11-06 Rietz, T., Schniter, E., Sheremeta, R., and Shields, T. Trust, Reciprocity and Rules.

11-05 Corgnet, B., Hernan-Gonzalez, R., and Rassenti, S. Real Effort, Real Leisure and Real-time Supervision: Incentives and peer pressure in virtual organizations. 
11-04 Corgnet, B. and Hernán-González R. Don’t Ask Me If You Will Not Listen: The dilemma of participative decision making.

11-03 Rietz, T., Sheremeta, R., Shields, T., and Smith, V. Transparency, Efficiency and the Distribution of Economic Welfare in Pass-Through Investment Trust Games.

11-02 Corgnet, B., Kujal, P. and Porter, D. The Effect of Reliability, Content and Timing of Public Announcements on Asset Trading Behavior.

11-01 Corgnet, B., Kujal, P. and Porter, D. Reaction to Public Information in Markets: How much does ambiguity matter?

\section{0}

10-23 Sheremeta, R. Perfect-Substitutes, Best-Shot, and Weakest-Link Contests between Groups.

10-22 Mago, S., Sheremeta, R., and Yates, A. Best-of-Three Contests: Experimental evidence.

10-21 Kimbrough, E. and Sheremeta, R. Make Him an Offer He Can't Refuse: Avoiding conflicts through side payments.

10-20 Savikhim, A. and Sheremeta, R. Visibility of Contributions and Cost of Inflation: An experiment on public goods.

10-19 Sheremeta, R. and Shields, T. Do Investors Trust or Simply Gamble?

10-18 Deck, C. and Sheremeta, R. Fight or Flight? Defending Against Sequential Attacks in the Game of Siege.

10-17 Deck, C., Lin, S. and Porter, D. Affecting Policy by Manipulating Prediction Markets: Experimental evidence.

10-16 Deck, C. and Kimbrough, E. Can Markets Save Lives? An Experimental Investigation of a Market for Organ Donations.

10-15 Deck, C., Lee, J. and Reyes, J. Personality and the Consistency of Risk Taking Behavior: Experimental evidence.

10-14 Deck, C. and Nikiforakis, N. Perfect and Imperfect Real-Time Monitoring in a Minimum-Effort Game.

10-13 Deck, C. and Gu, J. Price Increasing Competition? Experimental Evidence.

10-12 Kovenock, D., Roberson, B., and Sheremeta, R. The Attack and Defense of Weakest-Link Networks.

10-11 Wilson, B., Jaworski, T., Schurter, K. and Smyth, A. An Experimental Economic History of Whalers' Rules of Capture. 
10-10 DeScioli, P. and Wilson, B. Mine and Thine: The territorial foundations of human property.

10-09 Cason, T., Masters, W. and Sheremeta, R. Entry into Winner-Take-All and Proportional-Prize Contests: An experimental study.

10-08 Savikhin, A. and Sheremeta, R. Simultaneous Decision-Making in Competitive and Cooperative Environments.

10-07 Chowdhury, S. and Sheremeta, R. A generalized Tullock contest.

10-06 Chowdhury, S. and Sheremeta, R. The Equivalence of Contests.

10-05 Shields, T. Do Analysts Tell the Truth? Do Shareholders Listen? An Experimental Study of Analysts' Forecasts and Shareholder Reaction.

10-04 Lin, S. and Rassenti, S. Are Under- and Over-reaction the Same Matter? A Price Inertia based Account.

10-03 Lin, S. Gradual Information Diffusion and Asset Price Momentum.

10-02 Gjerstad, S. and Smith, V. Household Expenditure Cycles and Economic Cycles, 1920-2010.

10-01 Dickhaut, J., Lin, S., Porter, D. and Smith, V. Durability, Re-trading and Market Performance.

\section{9}

09-11 Hazlett, T., Porter, D., and Smith, V. Radio Spectrum and the Disruptive Clarity OF Ronald Coase.

09-10 Sheremeta, R. Expenditures and Information Disclosure in Two-Stage Political Contests.

09-09 Sheremeta, R. and Zhang, J. Can Groups Solve the Problem of Over-Bidding in Contests?

09-08 Sheremeta, R. and Zhang, J. Multi-Level Trust Game with "Insider" Communication.

09-07 Price, C. and Sheremeta, R. Endowment Effects in Contests.

09-06 Cason, T., Savikhin, A. and Sheremeta, R. Cooperation Spillovers in Coordination Games.

09-05 Sheremeta, R. Contest Design: An experimental investigation.

09-04 Sheremeta, R. Experimental Comparison of Multi-Stage and One-Stage Contests.

09-03 Smith, A., Skarbek, D., and Wilson, B. Anarchy, Groups, and Conflict: An experiment on the emergence of protective associations.

09-02 Jaworski, T. and Wilson, B. Go West Young Man: Self-selection and endogenous property rights.

09-01 Gjerstad, S. Housing Market Price Tier Movements in an Expansion and Collapse. 


\section{8}

08-09 Dickhaut, J., Houser, D., Aimone, J., Tila, D. and Johnson, C. High Stakes Behavior with Low Payoffs: Inducing preferences with Holt-Laury gambles.

08-08 Stecher, J., Shields, T. and Dickhaut, J. Generating Ambiguity in the Laboratory.

08-07 Stecher, J., Lunawat, R., Pronin, K. and Dickhaut, J. Decision Making and Trade without Probabilities.

08-06 Dickhaut, J., Lungu, O., Smith, V., Xin, B. and Rustichini, A. A Neuronal Mechanism of Choice.

08-05 Anctil, R., Dickhaut, J., Johnson, K., and Kanodia, C. Does Information Transparency Decrease Coordination Failure?

08-04 Tila, D. and Porter, D. Group Prediction in Information Markets With and Without Trading Information and Price Manipulation Incentives.

08-03 Thomas, C. and Wilson, B. Horizontal Product Differentiation in Auctions and Multilateral Negotiations.

08-02 Oprea, R., Wilson, B. and Zillante, A. War of Attrition: Evidence from a laboratory experiment on market exit.

08-01 Oprea, R., Porter, D., Hibbert, C., Hanson, R. and Tila, D. Can Manipulators Mislead Prediction Market Observers? 